
and Elisabetta Comini

\title{
Detection of volatile organic compounds: From chemical gas sensors to terahertz spectroscopy
}

https://doi.org/10.1515/revac-2021-0127

received: November 02, 2020; accepted: February 16, 2021

\begin{abstract}
Volatile organic compounds are released by different sources causing air pollution. Moreover, some of these carbon-based organic chemicals are considered as biomarkers in the exhaled breath of individuals and can be used to identify various kinds of diseases. Hence, the increasing demand to control air quality and human health has promoted the development of monitoring systems based on high-performance gas sensing structures. This review highlights the achievements in sensing technologies for the detection of volatile organic compounds. Particularly, chemiresistive gas sensors and detection systems based on the terahertz spectroscopy method are outlined. The progress in research studies is discussed and the potential of both techniques is evaluated considering the current challenges. Afterward, a brief summary is also provided along with the advances and issues for future investigations and the manufacturing of highly sensitive and selective monitoring systems.
\end{abstract}

Keywords: VOCs, metal oxide nanomaterials, chemical gas sensors, THz spectroscopy

\footnotetext{
* Corresponding author: Vardan Galstyan, Sensor Lab, Department of Information Engineering, University of Brescia, Via Valotti 9, 25133 Brescia, Italy,

e-mail: vardan.galstyan@unibs.it

Annalisa D'Arco: INFN-Rome1 P.le A. Moro 5, 00185, Rome, Italy; University of Rome 'La Sapienza', P.le A. Moro 5, 00185, Rome, Italy Marta Di Fabrizio: University of Rome ‘La Sapienza’, P.le A. Moro 5, 00185, Rome, Italy

Nicola Poli and Elisabetta Comini: Sensor Lab, Department of Information Engineering, University of Brescia, Via Valotti 9, 25133 Brescia, Italy

Stefano Lupi: University of Rome ‘La Sapienza’, P.le A. Moro 5, 00185, Rome, Italy; INFN-LNF Via E. Fermi 40, 00044 Frascati, Rome, Italy
}

\section{Introduction}

Volatile organic compounds (VOCs) belong to the family of toxic chemicals including hydrocarbons, alcohol, ketones, chlorine, and nitrogen-based compounds [1-4]. VOCs are produced by natural and/or anthropogenic sources [5-7]. Natural sources represent the metabolic processes in animals and living beings. Furthermore, the concentration variation of some VOCs in human exhaled breath is a symptom of gastrointestinal, respiratory, or metabolic pathologies [8,9]. For example, relatively high concentrations of acetone can be observed in the exhaled breath of diabetic patients. In addition, VOCs are emitted from industrial areas, waste burning, cooking, plants and many other sources resulting in the formation of oxidants, which are harmful to the ecosystem and human health [6-10].

Most of the VOCs have low boiling points and vaporize even at room temperature (RT) resulting in a rapid spread in the environment [6]. Hence, VOCs are considered indoor and outdoor air pollutants $[7,8]$. Therefore, the detection of VOCs to ensure the indoor and outdoor air quality is an important issue. Thus, the increasing demand for sensing systems for air quality and human health monitoring stimulates the development of advanced detection technologies [11-15].

There are different analytical methods based on chemical and physical principles for the detection of VOCs [16-18]. In this respect, the small size chemical gas sensors based on semiconductor materials can be applied as an effective tool for the detection and quantification analysis of VOCs [19-23]. The conductance of semiconductors is changed due to their interaction with reducing or oxidizing gases, which is used as a signal to identify the presence of different VOCs $[24,25]$. The importance of chemiresistive gas sensors has been highlighted by a large number of studies performed over the last few years, where the response, selectivity, stability, and operating temperature of the sensing structure have been improved to meet the requirements of modern 
monitoring systems [26-31]. The solid-gas interface plays a significant role in the interaction between the semiconductor and analyte [32]. Hence, the morphology of sensing material has a crucial effect on the improvement of its functionalities. Great emphasis has been placed on the preparation of nanostructured semiconductor materials. The increase in surface area to volume ratio, the variation of the shape and morphology of semiconductor nanostructures affect their sensing performance [31,33-38]. Meanwhile, the doping and functionalization of semiconductors may enhance their interaction with a specific analyte [39-42]. In this context, morphological, compositional, and structural effects on the sensing properties of metal oxide nanomaterials have been extensively studied for their integration into chemiresistive sensing devices [43-45].

In the meantime, progress has been made towards the development of new systems for the detection and identification of VOCs by spectroscopy methods including the vibrational spectroscopy [46-52].

Furthermore, new and advanced technologies based on optical sensors (including vibrational spectroscopy) may provide complementary approaches to conventional analytical methods for the detection and recognition of VOCs. Although these techniques have been proven to be able to detect various VOCs, the optical gas sensing systems can overcome issues related to chemiresistive gas sensors and exhibiting detection limits, demonstrating sensing characteristics comparable with gas chromatography. Among the optical sensing systems, the Terahertz (THz) spectroscopy is of increasing interest as a rapidly emerging technology in the field of analytical chemistry. It provides selective non-intrusive identification of polar gas molecules, through the interrogation of molecular roto-vibrational modes with $\mathrm{THz}$ radiation. Its potential is related to numerous absorption and emission molecular lines of interest suitable to recognize gas-phase VOCs, ensuring high selectivity and sensitivity. Thus, THz spectroscopy and the variability of the optical schemes offer several advantages, especially for practical applications in optically harsh environments, such as atmospheric, combustion, and industrial safety monitoring.

Herein, we outline the recent achievements in the detection of VOCs using two different approaches, namely the chemiresistive gas sensors and the $\mathrm{THz}$ spectroscopy. After a brief overview of both technologies, the discussion will be focused on the studies of chemical gas sensors and detection systems based on $\mathrm{THz}$ spectroscopy considering their potential for application in environmental and health monitoring systems.

\section{Operation principles}

\subsection{Chemical gas sensors}

Metal oxide nanomaterials are commonly used for the fabrication of chemical gas sensors [53-58]. They are solid structures that contain positively charged metal cations and the negative oxide anion [59]. The high-temperature stability, the tunable band gap and the established synthesis techniques of oxide materials make them very attractive for a wide range of applications [11,23,28,60-65]. Metal oxide nanostructures with different shapes and sizes can be synthesized by top-down and bottom-up methods using chemical and physical procedures (Figure 1a). The detailed description of the synthesis methods we have reported in our previous works $[25,37,66]$. A typical chemiresistive gas sensor based on metal oxide nanostructures is fabricated as follows: The sensing material is prepared on an insulating substrate. To perform the sensing measurements at different operating temperatures a platinum $(\mathrm{Pt})$ heater element and electrical contacts are deposited on the backside of the substrate and on the surface of semiconductor material, respectively (Figure $1 \mathrm{~b}$ ).

The operating principles of chemical gas sensors are based on the interaction mechanism of the analyte molecules with the sensing material. The atmospheric oxygen $\left(\mathrm{O}_{2}\right)$ adsorbs on an n-type semiconductor nanomaterial extracting electrons from its conduction band (Eq. 1 and $2,[32,68])$.

$$
\begin{aligned}
& O_{2}+e^{-} \leftrightarrows O_{2}^{-} \\
& O_{2}^{-}+e^{-} \leftrightarrows 2 O^{-}
\end{aligned}
$$

Consequently, an electron depleted layer and a potential barrier are formed at the grain boundaries of the material (Figure 2). The depletion width $(W)$ and the height of the potential barrier $\left(q V_{s}\right)$ are determined as follows:

$$
\begin{aligned}
& W=\sqrt{\frac{\varepsilon \varepsilon_{0} V_{s}}{q N_{d}}} \\
& q V_{S}=\frac{q^{2} N_{S}^{2}}{2 \varepsilon \varepsilon_{0} N_{d}}
\end{aligned}
$$

where $\varepsilon_{0}$ and $\varepsilon$ are the permittivity of vacuum and metal oxide material (unit, $\mathrm{F} \cdot \mathrm{m}^{-1}$ ), respectively, $V_{s}$ is the band bending (unit, eV), $q$ is the electrical charge of carrier (unit, Coulomb), $\mathrm{N}_{\mathrm{d}}$ is the concentration of charge carriers (unit, $\mathrm{m}^{-3}$ ), $N_{S}$ is the density of surface states (unit, number $\cdot \mathrm{cm}^{-2}$ ). The surface charge is determined by the 
(a)

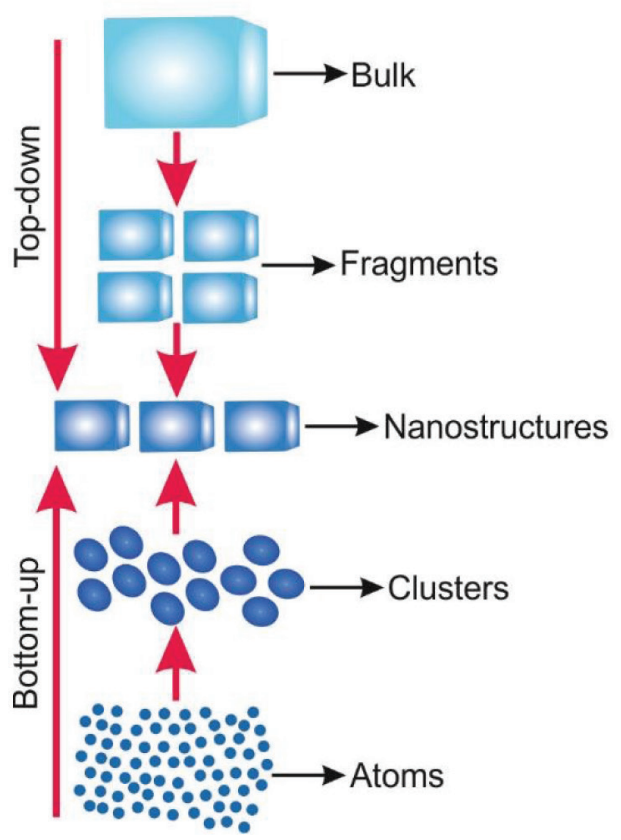

(b)

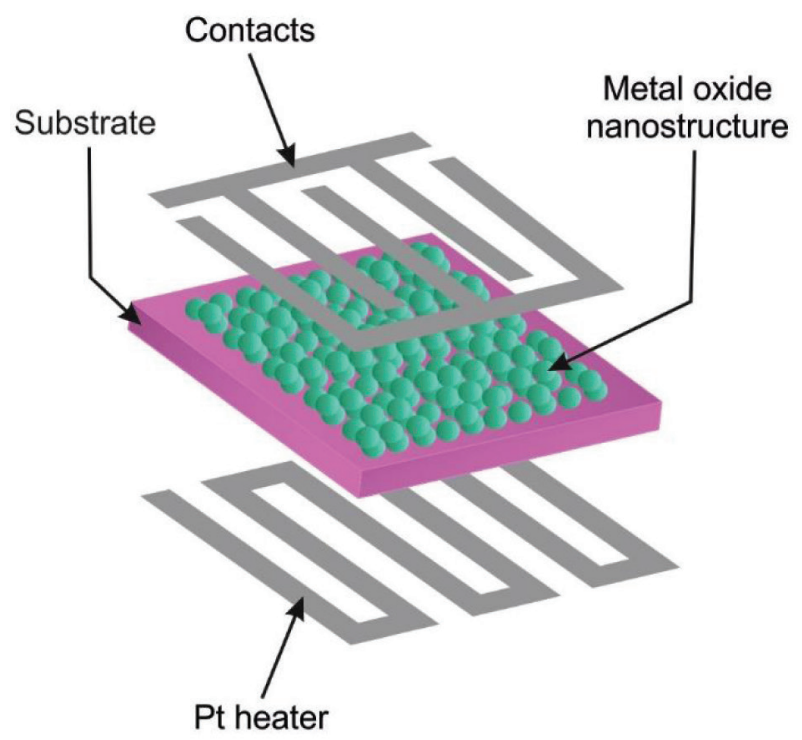

Figure 1: (a) The schematic representation of the top-down and bottom-up approaches for the fabrication of metal oxide nanostructures. Reprinted from Ref. [67]. (b) The schematic of a chemiresistive transducer (original image).

(a)

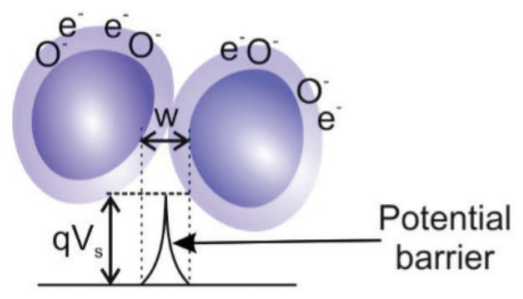

(b)

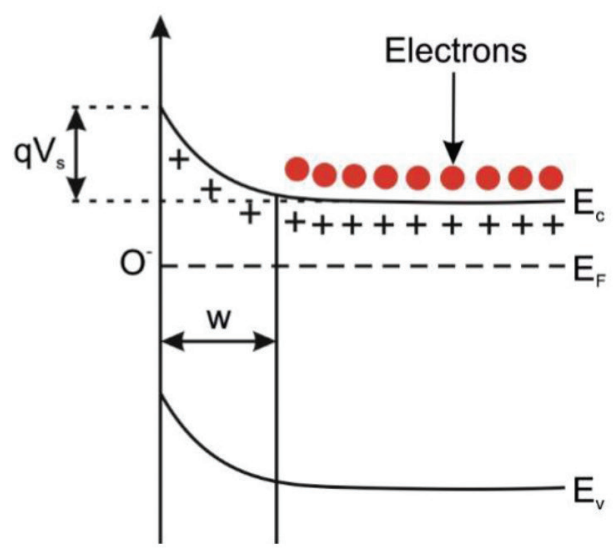

Figure 2: (a) A model showing the ionosorption of atmospheric oxygen and the formation of a potential barrier at the grain boundaries of metal oxide material. (b) The illustration of the band bending in the metal oxide structure due to the ionosorption of atmospheric oxygen on its surface, where $E_{c}, E_{v}$, and $E_{F}$ are the energy of the conduction band, valence band, and the Fermi level, respectively (original image).

concentration of ionosorbed oxygen and the Debye length ( $\mathrm{L}_{\mathrm{D}}$, in $\mathrm{nm}$, Eq. 5), where $k$ is the Boltzmann constant (units, $\mathrm{eV} \cdot \mathrm{K}^{-1}, \mathrm{~J} \cdot \mathrm{K}^{-1}$ ) and $T$ is the absolute temperature in Kelvin.

$$
L_{D}=\sqrt{\frac{\varepsilon \varepsilon_{0} k T}{q^{2} N_{d}}}
$$

The formation of ionosorbed oxygen species on the surface of the sensing materials is varied depending on its operating temperature. It has been demonstrated that $O^{-}$is a more active form and dominates at relatively high operating temperatures of semiconductor material (200$400^{\circ} \mathrm{C}$ ) [32]. Therefore, most of the chemiresistive gas sensors operate above $200^{\circ} \mathrm{C}$ [69]. If the sensing structure 
is an n-type oxide material, its electrical conductance will decrease due to the reduction of the concentration of free electrons (Figure 2). When a VOC $\left(r_{v o c}\right)$ is present in the atmosphere, it will react with the ionosorbed oxygen and will be oxidized restoring the conductance of the sensing structure (Eq. 6 and 7, [32,68]). Consequently, the conductance of p-type semiconductor materials will be varied in the opposite direction due to the adsorption of oxidizing and reducing gases on its surface.

$$
\begin{aligned}
& r_{v o c}+O_{2}^{-} \rightarrow r_{v o c} O_{2}+e^{-} \\
& r_{v o c}+O^{-} \rightarrow r_{v o c} O+e^{-}
\end{aligned}
$$

The aforementioned changes in the electrical parameters of sensing material affected by the gaseous species are used as the signal to detect the target VOCs [70]. Hence, the composition, structure, and morphology of the metal oxides including the chemical structure of the VOC are the key factors to determine the response, selectivity, and stability of gas sensors.

\subsection{THz spectroscopy}

Vibrational spectroscopy is a non-destructive optical approach that became one of the most promising directions in gas sensing technologies, due to its high sensitivity and selectivity, as well as its reagent free characteristic. Vibrational spectroscopy technique allows the development of high-performance detection systems for a continuous and simultaneous monitoring of multicomponent gaseous compounds compatible with online data processing [71-79].

The fundamentals of vibrational spectroscopy and the instrumental optical schemes have been widely discussed elsewhere [80-82]. In particular, for infrared (IR) and $\mathrm{THz}$ spectroscopy, the common approach is based on the irradiation of the confined gaseous compounds by light and the acquisition of their spectral information (Figure 3). The vibration transitions by mono and polyatomic molecules, that involve a change in dipole moment, result in the absorption of photons. For example, in many gases, IR/THz radiation excites molecular bonds (rotational and vibrational) resulting in specific absorption lines or bands in these electromagnetic spectral regions.

In the near-IR $\left(4000-14000 \mathrm{~cm}^{-1}\right)$ spectral region, the overtones of fundamental vibrations present in the mid-IR are observed. Here, powerful sensor technologies are available from telecommunication applications. However, many gases of interest for pollution and human breath analysis do not have absorption lines in this region or they are significantly weaker compared to the ones in mid-IR spectral range $\left(400-4000 \mathrm{~cm}^{-1}\right)$. In contrast, the majority of gases have main absorption lines in the spectral window of mid-IR, while polyatomic gases show dense and complex absorption spectra making difficult recognition of gas mixtures with the reduction of sensitivity without spectral deconvolution. Instead, in the $\mathrm{THz}$ spectral region (from nearly 3 to $300 \mathrm{~cm}^{-1}$, corresponding to $0.1-10 \mathrm{THz}$ ), the polar gases have relatively few lines
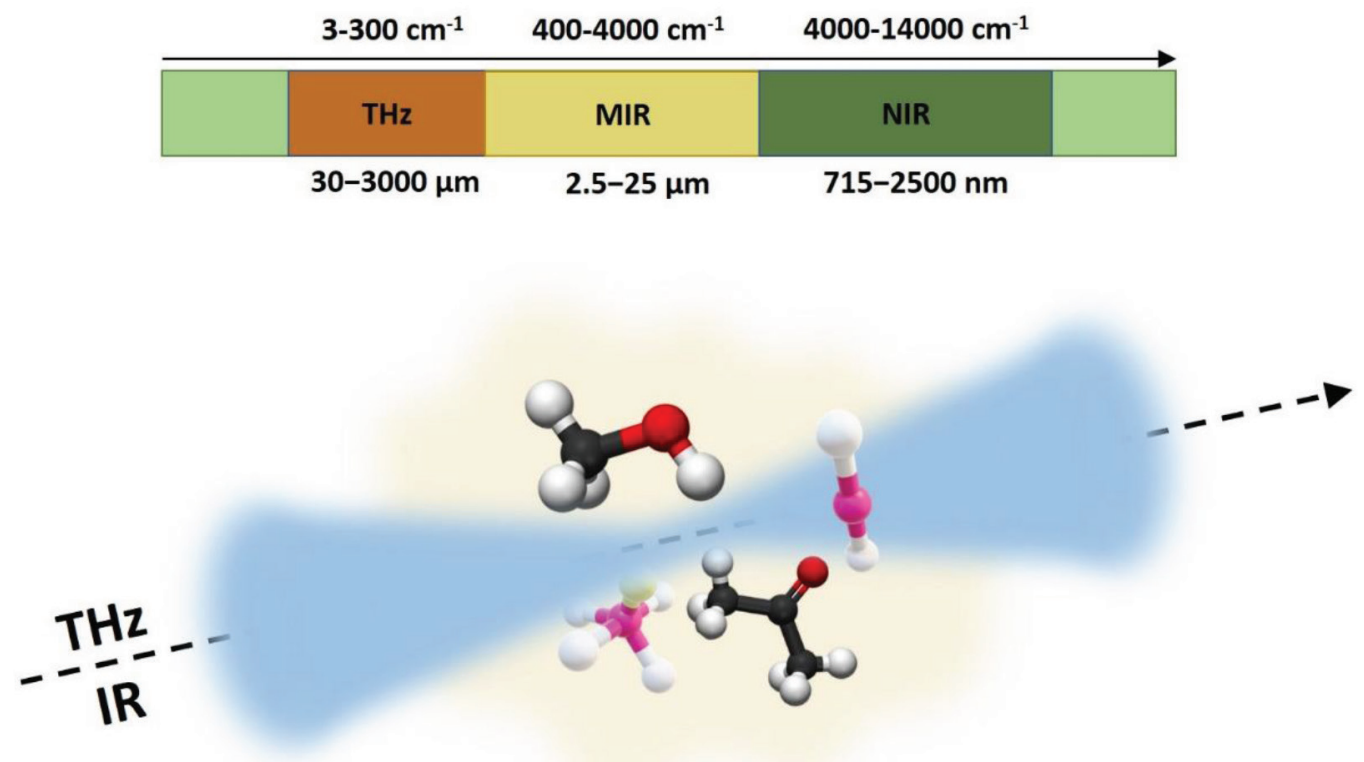

Figure 3: The interaction scheme in IR/THz vibrational spectroscopy with single- or multi-component gas mixtures. Typical frequency and wavelength ranges are shown for THz, MIR, and NIR (original image). 
showing superior properties to the IR technique in terms of spectral resolution, thus facilitating their specific and selective recognition [83]. This high selectivity in the $\mathrm{THz}$ region is a crucial point to define the analytical utility for gas-phase sensing applications.

First of all, THz radiation has a low photon energy (4meV @ 1THz) that cannot ionize molecules and is not sufficient to cause combustion in inflammable materials [84-86]. Moreover, it strongly interacts with polar molecules (more than the microwave spectral region [87-90]), while nonpolar materials (like paper, cloths, and plastic) are usually transparent in $\mathrm{THz}$ range [91]. The strength of the absorption in the $\mathrm{THz}$ spectral range for gas molecules is on the same order of magnitude of mid-IR range and from $10^{3}$ to $10^{6}$ times stronger than that in the microwave region [92]. In addition, the $\mathrm{THz}$ time-domain spectroscopy (THz-TDS) has advantages compared to the Fourier-transform IR (FT-IR) spectroscopy: it is not sensitive to the thermal background, shows a higher SNR and does not require the use of cooled detectors [82].

Moreover, the photon energy of $\mathrm{THz}$ waves coincides with energy levels corresponding to low-frequency motions, such as vibration, rotation, and translation modes of molecules in their condensed phases as well as the intermolecular vibrations, such as hydrogen bonds [85].
The most used system as substance identification tool is the THz-TDS technique, both in single and in multi-component VOCs mixtures in liquid- and gas-phase [93-102]. The working principle of a THz-TDS scheme is based on the detection (mostly in transmission or reflection modes) of a broadband $\mathrm{THz}$ source (typically ranging from hundreds of $\mathrm{GHz}$ to some $\mathrm{THz}$ ) after its interaction with the sample [85,103]. Many schemes and materials can be used for THz wave collection in THz-TDS [104-106] with coherent detection mode [107]. Thus, both amplitude and phase of the THz pulse electric field can be simultaneously measured and the optical parameters including sample absorption coefficient and refractive index can be extracted without using Kramers-Kronig relations [84,85]. The optical features of sample may be evaluated by collecting the $\mathrm{THz}$ waveform after the interaction with the sample and comparing it with the reference $\mathrm{THz}$ pulse (no sample inserted in the optical path). Figure 4a reports the schematic layout of the THz-TDS setup available at Terahertz laboratory (University of Rome 'La Sapienza', [108,109]).

The spectral resolution depends on the total length of the optical delay line (DL) scanning used to reconstruct the $\mathrm{THz}$ pulse. Consequently, the longer the length, the higher the resolution. A spectral resolution of some $\mathrm{GHz}$ can be reached with a typical THz-TDS scheme [92].
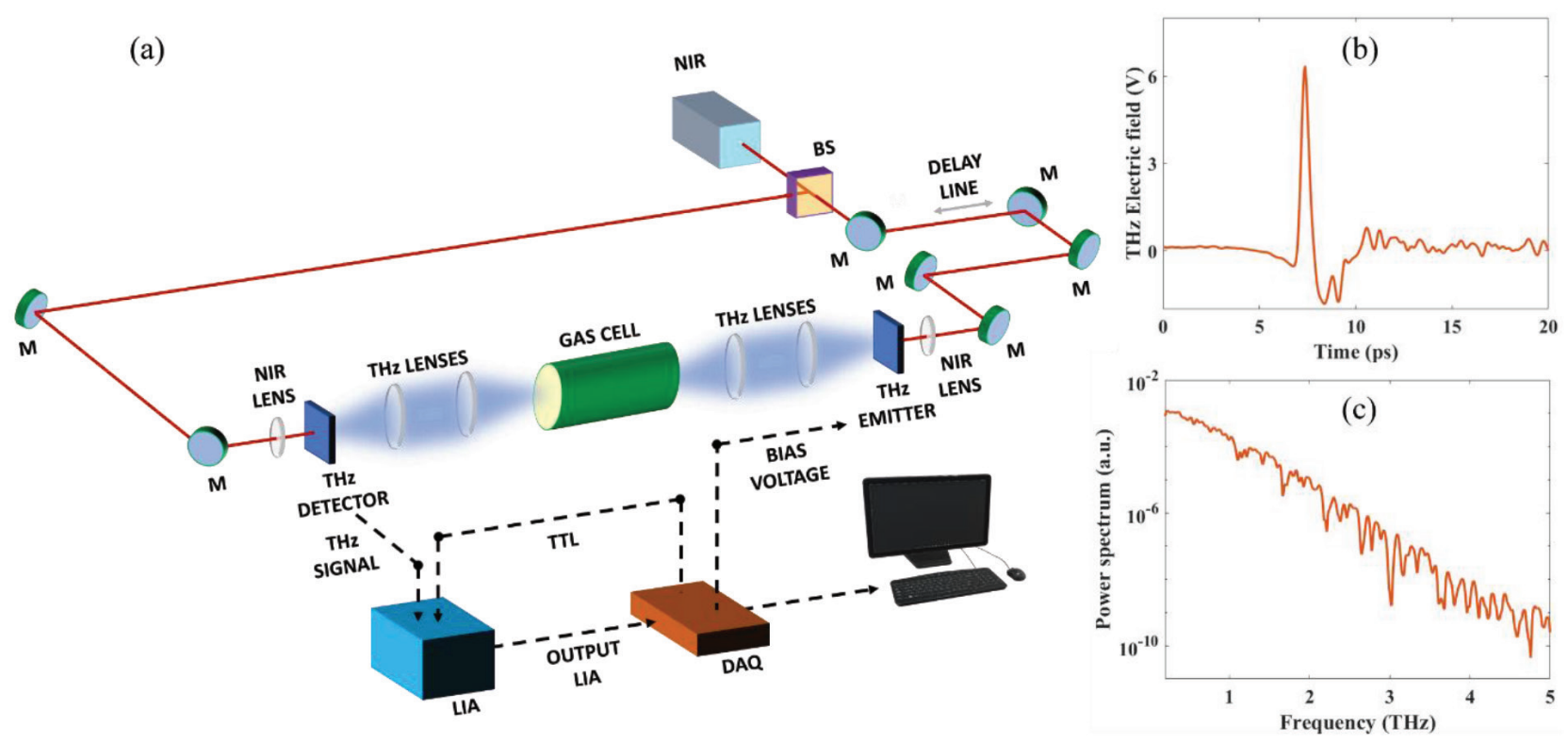

Figure 4: (a) Schematic layout of a typical THz-TDS setup in transmission mode based on switched photoconductive antennas (PCAs). A femtosecond near-IR (NIR) laser beam is divided in two parts by a beam splitter. Some mirrors $(M)$ convey the laser beams to the THz emitter and receiver, where they are focused by a NIR lens. Here the THz beam is produced and detected, respectively. A stack of transparent THz lenses collimates and focuses THz radiation along the path and a gas cell is inserted into the THz propagation region. The acquisition chain consists of a Lock-in amplifier (LIA), a data acquisition card (DAQ) and a personal computer for data collection and analysis. The optical delay line is used to sample the THz pulse in the time domain. (b) Temporal profile of THz electric field. (c) Power spectrum as a function of THz frequency. The presented THz-TDS setup is available at Terahertz laboratory, University of Rome 'La Sapienza' (original image). 


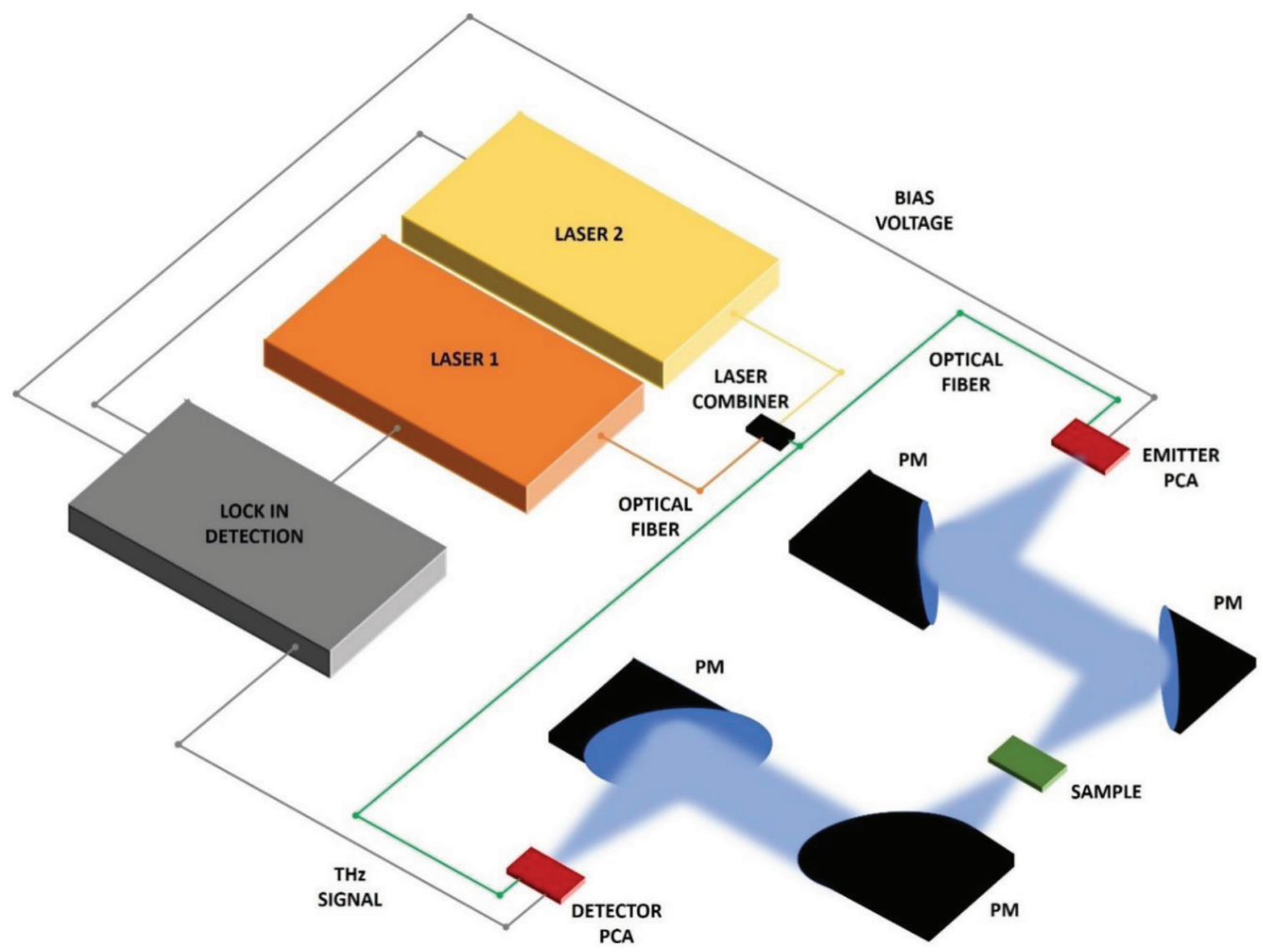

Figure 5: Schematic layout of THz-FDS setup. Two continuous wave tunable lasers at adjacent frequencies beat in a laser combiner and illuminate the $\mathrm{THz}$ emitter and receiver for $\mathrm{THz}$ generation and detection. Optical fibers are used to carry out laser signals. A 4-parabolic mirror (PM) system collimates and focuses THz radiation along the path. If only 2-PM system is used the sample is placed in the collimated region of the $\mathrm{THz}$ beam. The acquisition chain is based on lock in detection (original image).

THz-FDS is closely related to TDS in physical processes, measurement and detection scheme [110]. It typically operates in the frequency range of 0.05 to $3 \mathrm{THz}$ [111]. In comparison to the TDS, the main advantages of FDS are the high frequency resolution $\sim \mathrm{MHz}$, the possibility to work at a fixed frequency or in frequency range, the relatively low cost of system and the fact that does not need Fourier Transform algorithms for spectral analysis. Figure 5 shows the schematic representation of a typical THz-FDS setup. Like the THz-TDS, the coherent detection mode is adopted, however, no delay line is present because no temporal profile of $\mathrm{THz}$ pulse is acquired during the measurement.

\section{Functionalities of chemical gas sensors}

Extensive efforts have been made on the integration of oxide nanostructures in chemical sensing devices since they exhibit enhanced functionalities compared to those of bulk materials $[27,29,45,112]$. The sensing parameters of metal oxide nanostructures for the detection of VOCs are listed in Table 1. It is well known that the most popular metal oxide that has been used for the manufacturing of chemiresistive gas sensors is the tin dioxide $\left(\mathrm{SnO}_{2}\right)$. The preparation of $\mathrm{SnO}_{2}$ nanostructures with different shapes increases the specific surface area of the material affecting its sensitivity towards a wide range of VOCs [113-116]. Hence, the grain size plays a crucial role in the enhancement of sensing properties of $\mathrm{SnO}_{2}$ [117]. When the grain size of $\mathrm{SnO}_{2}$ is comparable to $2 \mathrm{~L}_{\mathrm{D}}$, the grains are fully depleted by electrons enhancing the sensing response of the material. For example, the reduction of $\mathrm{SnO}_{2}$ particle size to $2-5 \mathrm{~nm}$ increased the concentration of surface oxygen vacancies and improved the sensing performance of structure to ethanol at a relatively low operating temperature $\left(230^{\circ} \mathrm{C}\right)$ [33]. Li et al. obtained $\mathrm{SnO}_{2}$ spherical structures with a crystallite size of $8 \mathrm{~nm}$ and the material exhibited a high sensing response towards formaldehyde $\left(\mathrm{H}_{2} \mathrm{CO}\right)$ at $200^{\circ} \mathrm{C}[113]$. In order to improve the performance 
Table 1: Sensing parameters of metal oxide nanostructures for the detection of VOCs at their optimum operating conditions

\begin{tabular}{|c|c|c|c|c|c|c|c|}
\hline $\begin{array}{l}\text { Material/ } \\
\text { morphology }\end{array}$ & $\begin{array}{c}\text { Operating } \\
\text { temperature } \\
\left({ }^{\circ} \mathrm{C}\right)\end{array}$ & $\begin{array}{l}\text { Analyte, } \\
\text { concentration (ppm) }\end{array}$ & Response & $\begin{array}{c}\text { Response/ } \\
\text { recovery } \\
\text { time (s) }\end{array}$ & $\begin{array}{l}\text { LOD } \\
(\mathrm{ppb})\end{array}$ & $\begin{array}{l}\text { Stability/ } \\
\text { reproducibility }\end{array}$ & Ref. \\
\hline $\mathrm{SnO}_{2}$ microspheres & 200 & $\mathrm{H}_{2} \mathrm{CO}, 100$ & $R_{a} / R_{g}, 38$ & $17 / 25$ & - & 6 cycles $^{\dagger}$ & [113] \\
\hline $\mathrm{SnO}_{2}$ microspheres & 230 & Ethanol, 100 & $\mathrm{R}_{\mathrm{a}} / \mathrm{R}_{\mathrm{g}}, 25$ & $3 / 24$ & 500 & 6 cycles & [33] \\
\hline $\mathrm{SnO}_{2}$ nanowire & 450 & Ethanol, 25 & $V_{g} / V_{a} 6.1$ & $15 / 41$ & - & - & [114] \\
\hline $\mathrm{SnO}_{2}$ hollow spheres & 250 & $\mathrm{H}_{2} \mathrm{CO}, 200$ & $\mathrm{R}_{\mathrm{a}} / \mathrm{R}_{\mathrm{g}}, 194$ & $190 / 35$ & - & - & [115] \\
\hline $\mathrm{SnO}_{2}$ hollow spheres & 250 & 2-propanol, 200 & $\mathrm{R}_{\mathrm{a}} / \mathrm{R}_{\mathrm{g}}, 237$ & $145 / 100$ & - & 15 days & [115] \\
\hline $\mathrm{SnO}_{2}$ hollow spheres & 350 & Toluene, 200 & $R_{a} / R_{g}, 14$ & $130 / 200$ & - & - & [115] \\
\hline $\mathrm{SnO}_{2}$ hollow spheres & 250 & Methanol, 200 & $\mathrm{R}_{\mathrm{a}} / \mathrm{R}_{\mathrm{g}}, 79$ & $340 / 130$ & - & - & [115] \\
\hline $\mathrm{SnO}_{2}$ nanorings & 250 & Isopropanol, 100 & $\mathrm{I}_{\mathrm{g}} / \mathrm{I}_{\mathrm{a}}, 7.3$ & $7 / 39$ & 1000 & 10 cycles & [116] \\
\hline $\mathrm{a}-\mathrm{Fe}_{2} \mathrm{O}_{3}$ nanowires & 280 & Ethanol, 100 & $R_{a} / R_{g}, 45$ & $16 / 28$ & - & 6 cycles & [118] \\
\hline $\mathrm{WO}_{3}$ nanoparticles & 400 & Acetone, 0.5 & $\left(I_{g}-I_{a}\right) / I_{a}, 2.3$ & $330 / 180$ & 170 & - & [120] \\
\hline $\ln _{2} \mathrm{O}_{3}$ nanoparticles & 100 & $\mathrm{H}_{2} \mathrm{CO}, 10$ & $R_{a} / R_{g}, 68$ & $122 / 39$ & 1000 & 1 month & {$[34]$} \\
\hline $\mathrm{NiO}$ nanocuboinds & 120 & acetoin, 50 & $\mathrm{R}_{\mathrm{g}} / \mathrm{R}_{\mathrm{a}}, 302$ & $92 / 82$ & 500 & 36 days & [35] \\
\hline $\mathrm{ZnO}$ nanorods & 300 & Ethanol, 100 & $\mathrm{R}_{\mathrm{a}} / \mathrm{R}_{\mathrm{g}}, 45$ & $6 / 31$ & - & 30 days & {$[36]$} \\
\hline ZnO nanobristles & RT & Ethanol, 100 & $R_{a} / R_{g}, 464$ & $19 / 12$ & - & 3 cycles & [122] \\
\hline $\mathrm{TiO}_{2}$ nanograins & 450 & Ethanol, 150 & $\mathrm{R}_{\mathrm{a}} / \mathrm{R}_{\mathrm{g}}, 6$ & $-/ 600$ & 700 & 3 cycles & [119] \\
\hline $\mathrm{Pt}-\mathrm{TiO}_{2}$ & 300 & Acetone, 200 & $\mathrm{R}_{\mathrm{a}} / \mathrm{R}_{\mathrm{g}}, 29$ & $13 / 30$ & - & 30 days & [137] \\
\hline $\mathrm{Pd}-\ln _{2} \mathrm{O}_{3}$ nanoparticles & 350 & Ethanol, 5 & $\mathrm{R}_{\mathrm{a}} / \mathrm{R}_{\mathrm{g}}, 159$ & - & - & - & [121] \\
\hline Pt- $\ln _{2} \mathrm{O}_{3}$ nanofibers & 180 & Acetone, 50 & $\mathrm{R}_{\mathrm{a}} / \mathrm{R}_{\mathrm{g}}, 105$ & $6 / 9$ & 10 & 50 days & [126] \\
\hline $\mathrm{Pd}-\mathrm{Au}-\mathrm{SnO}_{2}$ nanosheets & 250 & Acetone, 2 & $R_{a} / R_{g}, 6.5$ & $5 / 4$ & 45 & 6 cycles & [41] \\
\hline $\mathrm{Ag}-\mathrm{SnO}_{2}$ nanofibers & 100 & Acetone, 50 & $R_{a} / R_{g}, 40$ & $6 / 10$ & - & 4 cycles & [127] \\
\hline $\begin{array}{l}\mathrm{Y}-\mathrm{SnO}_{2} \text { flower-shaped } \\
\text { nanostructures }\end{array}$ & 180 & $\mathrm{H}_{2} \mathrm{CO}, 50$ & $R_{a} / R_{g}, 18$ & - & 1000 & 2 months & {$[42]$} \\
\hline $\mathrm{Ni}-\mathrm{SnO}_{2}$ nanorods & 450 & Ethanol, 50 & $R_{a} / R_{g}, 2000$ & $30 / 600$ & - & - & [128] \\
\hline $\mathrm{Fe}-\mathrm{ZnO}$ Nanosheet-Spheres & 300 & $\mathrm{H}_{2} \mathrm{CO}, 10$ & $R_{a} / R_{g}, 33$ & $42 / 11$ & - & - & [138] \\
\hline Al-NiO nanofibers & 325 & Methanol, 200 & $R_{g} / R_{a}, 10$ & $199 / 15$ & - & 4 cycles & [139] \\
\hline $\mathrm{Ag}-\left(\mathrm{TiO}_{2} / \mathrm{SnO}_{2}\right)$ & 275 & Ethanol, 50 & $R_{a} / R_{g}, 53$ & $3.5 / 7$ & 1000 & 30 days & [134] \\
\hline $\mathrm{CuO} / \mathrm{Ti}_{3} \mathrm{C}_{2} \mathrm{~T}_{\mathrm{x}}$ nanoparticles & 250 & Toluene, 50 & $\mathrm{R}_{\mathrm{g}} / \mathrm{R}_{\mathrm{a}}, 11$ & $270 / 10$ & 320 & - & [13] \\
\hline $\mathrm{NiO} / \mathrm{SnO}_{2}$ nanoparticles & RT & Ethanol, 100 & $\mathrm{R}_{\mathrm{g}} / \mathrm{R}_{\mathrm{a}}, 140$ & $23 / 13$ & 1000 & - & [136] \\
\hline $\mathrm{SnO}_{2} / \mathrm{NiO} / \mathrm{Au}$ hollow sphere & 75 & Ethanol, 40 & $\left(R_{a}-R_{g}\right) / R_{g}, 38$ & - & - & 35 days & [133] \\
\hline $\mathrm{TiO}_{2} / \mathrm{SnO}_{2}$ branched mesopores & 350 & Ethanol, 50 & $R_{a} / R_{g}, 40$ & $7 / 5$ & 200 & 30 days & [131] \\
\hline $\begin{array}{l}\mathrm{TiO}_{2} / \mathrm{WSe}_{2} \text { nanospheres/ } \\
\text { nanosheets }\end{array}$ & RT & Ethanol, 30 & $R_{g} / R_{a}, 10$ & $2 / 2$ & - & 1 month & [29] \\
\hline $\mathrm{Y}_{2} \mathrm{O}_{3} / \mathrm{ZnO}$ nanoparticles & RT & 2-methoxyethanol, 100 & $R_{g} / R_{a}, 599$ & $17 / 21$ & - & 30 days & [135] \\
\hline
\end{tabular}

$R_{a}$ and $R_{g}$ are the resistance values of structures in air and in the presence of analyte, respectively. $I_{a}$ and $I_{g}$ are the conductance values of structures in air and in the presence of analyte, respectively. $V_{a}$ and $V_{g}$ are the voltage drop measured across the reference resistor in presence of the analyte and in air. ${ }^{\dagger}$ Cycles of sensing tests performed at the same operating conditions. 
of conventional gas sensors, the functional properties of many other metal oxide nanostructures, such as $\mathrm{ZnO}, \mathrm{Fe}_{2} \mathrm{O}_{3}, \mathrm{TiO}_{2}, \mathrm{WO}_{3}, \mathrm{NiO}$, and $\mathrm{In}_{2} \mathrm{O}_{3}$ have been studied [34-36,118-120].

The stability of the functional parameters of the fabricated sensors was analyzed from a few cycles to a few tenths of days using the same test protocol (Table 1). The obtained results mainly indicate the reliability of chemical sensors based on metal oxide nanomaterials. However, the tests should be performed for longer periods to confirm their long-term stability.

In general, the high activation energies are in need to improve the interaction between the semiconductor materials and VOCs [32,67,114,121]. As can be seen in Table 1, some sensing structures based on pure oxide nanomaterials showed a good response towards VOCs at relatively low operating temperatures, which is another important achievement and favorable for the manufacturing of low power consumption detection systems. For example, $\operatorname{In}_{2} \mathrm{O}_{3}$ nanoparticles with the dimension of 2-15 nm exhibited a high response towards $\mathrm{H}_{2} \mathrm{CO}$, at $100^{\circ} \mathrm{C}$ [34]. Moreover, $\mathrm{ZnO}$ nanobristles showed good and reproducible sensing performance towards ethanol at room temperature (RT) [122]. However, the water $\left(\mathrm{H}_{2} \mathrm{O}\right)$ vapor can be adsorbed on the chemical gas sensors at RT affecting their functionalities [66]. Therefore, the humidity effect on the VOC sensors should be considered in detail to determine their operating temperature. In the meantime, the crystal structure of oxide materials may affect their sensing response [123]. Recently, it has been demonstrated that the crystalline phase of $\mathrm{WO}_{3}$ nanoparticles has a significant effect on their response and selectivity towards acetone [122]. In particular, the monoclinic $\mathrm{y}-\mathrm{WO}_{3}$ crystalline phase is more reactive compared to the orthorhombic $\beta-\mathrm{WO}_{3}$. Furthermore, the large dipole moment of monoclinic $\gamma-\mathrm{WO}_{3}$ can enhance the interaction of the material with a polar compound such as acetone affecting its selectivity (Figure 6).

The overall findings suggest that metal oxide nanomaterials with various shapes are very promising structures for the application in VOC detection systems (Table 1). It should be noted that the harmful effects caused by VOCs depend on their type and concentration [6,7]. Furthermore, the identification of the exact concentration of VOCs in human exhaled breath is important to evaluate the human health status $[124,125]$. In this respect, it is of great significance to identify the smallest concentration of the analyte (so-called limit of detection (LOD)) that can be detected by the chemical gas sensors. Unfortunately, the LOD of most of the fabricated sensors was not evaluated (Table 1).
The conductance of metal oxide nanostructures can be affected due to the adsorption and desorption processes of different VOCs on their surface. Therefore, the selectivity of chemical sensors is one of the major issues that should be overcome. Different strategies to enhance the response and selectivity of metal oxide sensors have been utilized. One of the most common approaches to improve the performance of chemiresistive sensors is the functionalization of oxide materials with catalytic materials. Noble metals can be used to activate the reactions between the oxide materials and specific VOCs. Gold (Au), palladium (Pd), and Pt nanoparticles affect the dissociation of atmospheric $\mathrm{O}_{2}$ on the surface of metal oxides increasing the concentration of adsorption sites for VOCs, while the response of the sensors towards oxidizing gases will be decreased (Figure 7, [121,126]). Meanwhile, the electronic sensitization of noble metals plays a significant role in the functionalities of chemical sensors due to the formation of a potential barrier (Schottky barrier) and the increase of the thickness of the depletion layer at the interface between oxide material and catalyst. Hence, the electrons are released more readily from the surface reactions at the noble metal/metal oxide interface to the conduction band and affect the electron charge transfer dynamics [42,121]. Moreover, the functionalization of $\mathrm{SnO}_{2}$ nanofibers with silver $(\mathrm{Ag})$ nanoparticles and further oxidation of $\mathrm{Ag}$ to the $\mathrm{Ag}_{2} \mathrm{O}$ leads to the formation of a $\mathrm{p}-\mathrm{n}$ heterojunction. Consequently, the formed heterojunction between the n-type $\mathrm{SnO}_{2}$ and p-type $\mathrm{Ag}_{2} \mathrm{O}$ increases the width of the depletion layer of $\mathrm{SnO}_{2}$ affecting the structure response to acetone [127]. However, the aforementioned investigations indicate that the catalytic layers accelerate the interaction processes of oxide materials with VOCs mainly enhancing the response of sensors. Therefore, understanding the behavior of each catalyst to make the sensors sensitive to a particular VOC is an important issue and should be further studied.

The doping of metal oxide nanomaterials is another effective way to enhance their response and selectivity towards VOCs. The incorporation of dopant materials into the structure of metal oxides will introduce crystal defects, which will lead to the formation of oxygen vacancies enhancing the interaction of the material with VOCs [40,42,123,128]. Furthermore, the dopants with a higher oxidation state may replace the atoms of metal oxides maintaining the same oxidation state of the nanostructure, and thus increase its electrical conductivity $[39,129]$. This is an important factor to read out the conductance change (sensing signal) of metal oxide gas sensors using cost-effective and small size electrical devices. As we have mentioned before, the crystal structure of material may 
(a)

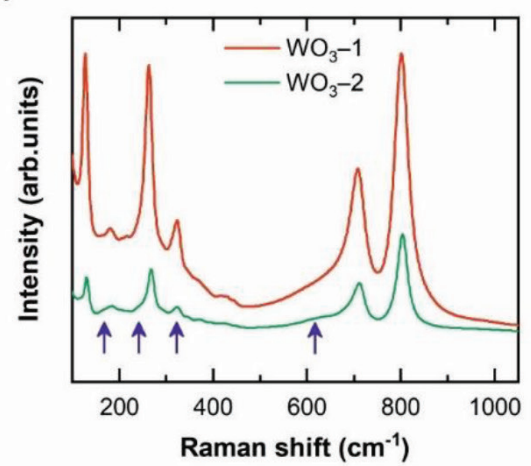

(c)

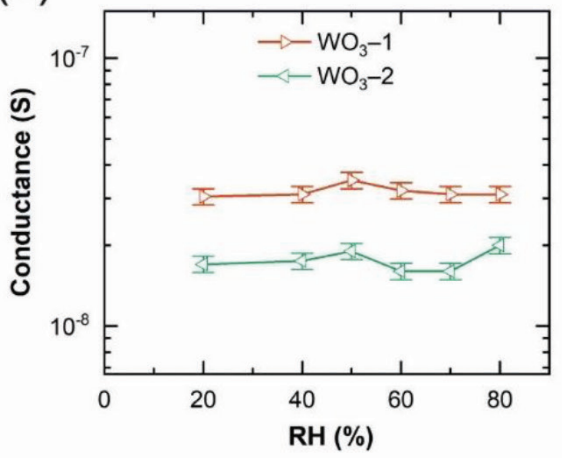

(e)

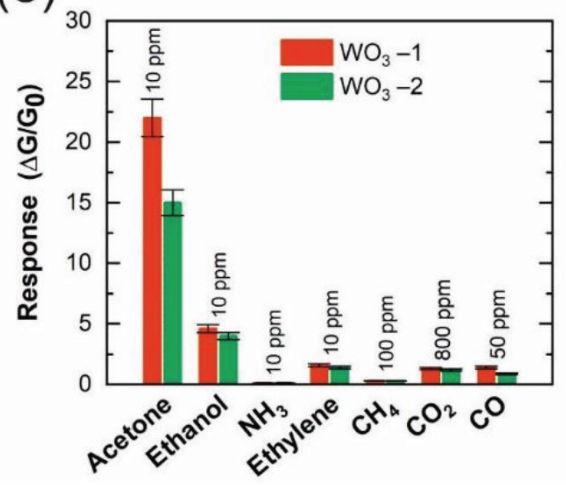

(b)

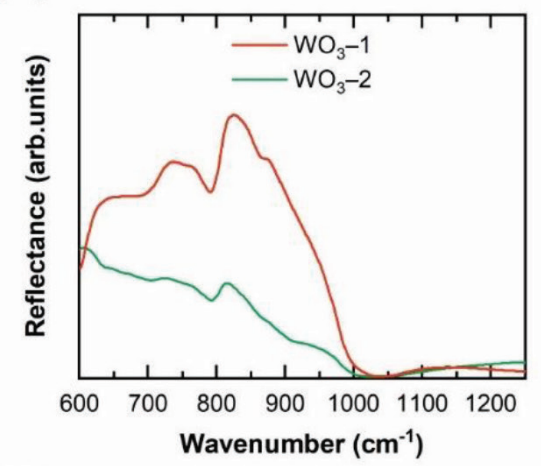

(d)

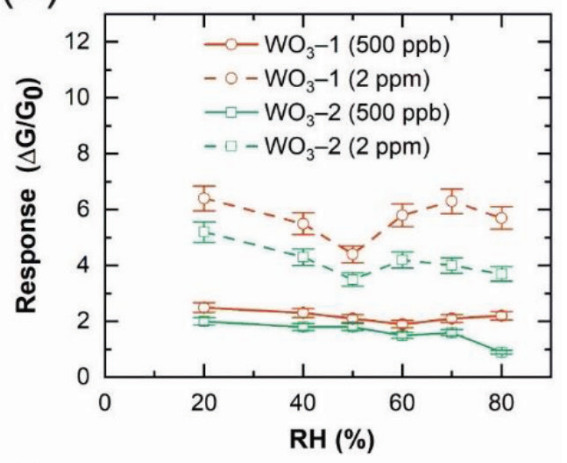

(f)

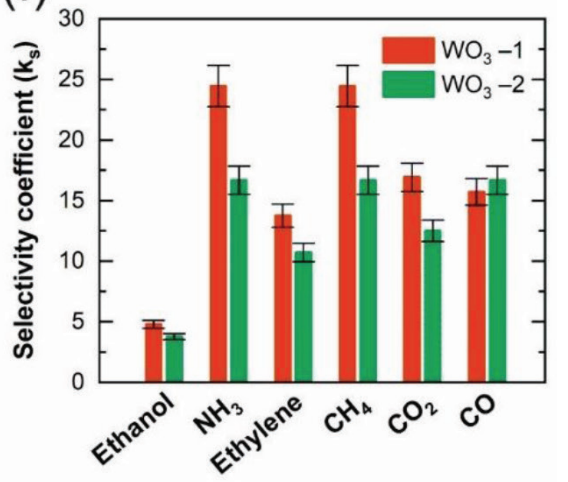

Figure 6: (a) Raman spectra of $\mathrm{WO}_{3}-1^{\dagger}$ and $\mathrm{WO}_{3}-2$ !" structures. The blue arrows in the spectrum of $\mathrm{WO}_{3}-2$ show the orthorhombic $\beta$-WO phase. (b) FTIR reflectance spectra of $\mathrm{WO}_{3}-1$ and $\mathrm{WO}_{3}-2$ in the spectral region between 600 and $1200 \mathrm{~cm}^{-1}$. (c) Conductance dependence of $\mathrm{WO}_{3}-1$ and $\mathrm{WO}_{3}-2$ from the concentration of $\mathrm{RH}$ at $400^{\circ} \mathrm{C}$. (d) Response values of $\mathrm{WO}_{3}-1$ and $\mathrm{WO}_{3}-2$ to $500 \mathrm{ppb}$ and $2 \mathrm{ppm}$ of acetone at different concentrations of $\mathrm{RH}$. (e) Response of $\mathrm{WO}_{3}-1$ and $\mathrm{WO}_{3}-2$ towards acetone, ethanol, ammonia $\left(\mathrm{NH}_{3}\right)$, ethylene, methane $\left(\mathrm{CH}_{4}\right)$, carbon dioxide $\left(\mathrm{CO}_{2}\right)$, and carbon monoxide (CO) at $400^{\circ} \mathrm{C}$. (f) Selectivity of $\mathrm{WO}_{3}-1$ and $\mathrm{WO}_{3}-2$ against interfering gases at $400^{\circ} \mathrm{C}(\mathrm{ks}$ was calculated using the response values of sensors towards $10 \mathrm{ppm}$ of acetone with respect to their response values towards ethanol (10 ppm), $\mathrm{NH}_{3}(10 \mathrm{ppm})$, ethylene $(10 \mathrm{ppm}), \mathrm{CH}_{4}(100 \mathrm{ppm}), \mathrm{CO}_{2}(800 \mathrm{ppm})$, and $\mathrm{CO}(50 \mathrm{ppm})$. Because the $\mathrm{WO}_{3}-1$ and WO $\mathrm{W}_{3}-2$ structures are almost not sensitive to $\mathrm{NH}_{3}$ and $\mathrm{CH}_{4}$, for our calculations, we considered the response values of both materials to the aforementioned gases to be 0.9. ${ }^{+} \mathrm{WO}_{3}$ nanoparticles crystallized into the monoclinic $\mathrm{\gamma}-\mathrm{WO}_{3}$ phase. " $\mathrm{WO}_{3}$ nanoparticles crystallized into the monoclinic $\mathrm{\gamma}$-WO $\mathrm{W}_{3}$ and orthorhombic $\beta-\mathrm{WO}_{3}$ phase. Reprinted with permission from Ref. [120]. Copyright 2020, The Royal Society of Chemistry (RSC).

affect its reactivity [123]. The semiconductor gas sensors mainly operate at elevated temperatures, where is possible a structural phase transition in the sensing material $[123,130]$. The phase transition will destabilize the functional properties of sensing devices. In this regard, some dopant materials may inhibit the phase transition effect at high operating temperatures and stabilize the sensing performance of metal oxides [123].

To improve the electronic and sensing properties of metal oxides is possible by coupling them in more complex structures achieving a synergetic effect between different materials (Figure 8, [131,132]). Recent studies 
(a)
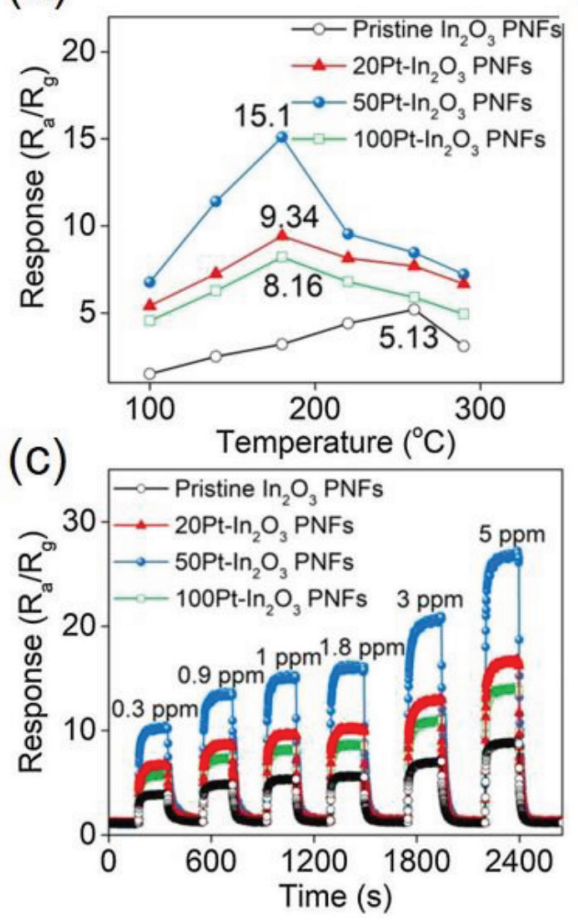

(b)

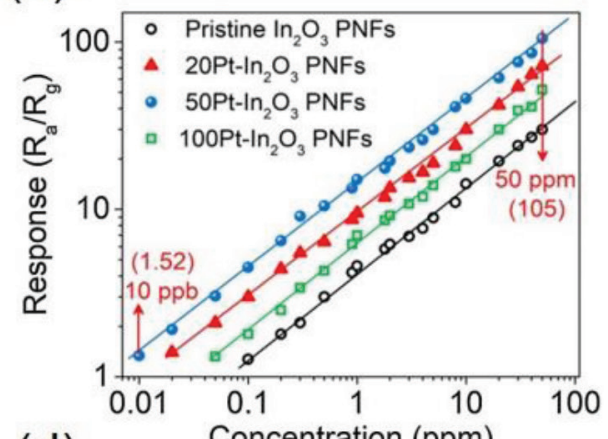

(d)

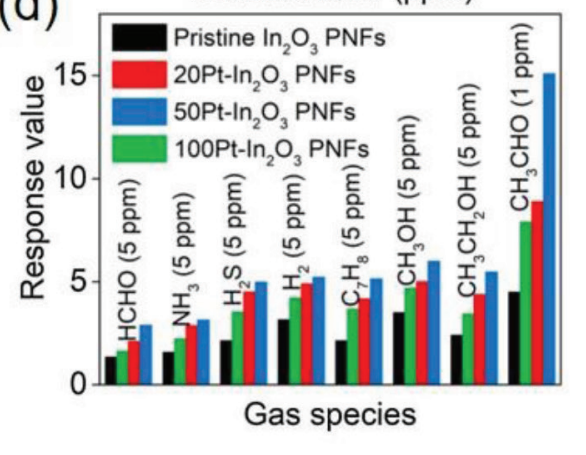

Figure 7: (a) The sensors' response to $1 \mathrm{ppm}$ acetone versus the working temperature, (b) the dynamic response curves in the concentration range of $0.3-5 \mathrm{ppm},(\mathrm{c})$ the linear relationship between response and acetone concentrations, (d) the selectivity tests for the pristine $\mathrm{In}_{2} \mathrm{O}_{3}$ $\mathrm{PNFs}^{\ddagger}$ and 20/50/100 Pt- $\operatorname{In}_{2} \mathrm{O}_{3}$ PNFs sensors. ${ }^{\ddagger}$ Porous nanofibers. Reprinted with permission from Ref. [126]. Copyright 2019, Elsevier.

suggest that this is a very efficient strategy to improve the response and selectivity of chemical sensors towards a specific VOC. A wide range of oxide materials can be used for the development of sensors based on composite structures [131,133-135]. Moreover, the research findings show that the coupling of semiconductor nanomaterials with different types of conductivity will result in the formation of a p-n heterojunction, where the modulation of the junction due to the interaction of the composite structure with VOCs plays a critical role in the performance of the sensing device at low operating temperatures. Jayababu, et al. reported that the formation of a $\mathrm{p}-\mathrm{n}$ junction between the $\mathrm{n}-\mathrm{SnO}_{2}$ and $\mathrm{p}-\mathrm{NiO}$ resulted in the transfer of electrons from $\mathrm{SnO}_{2}$ to $\mathrm{NiO}$ and in the transfer of holes in the opposite direction creating a depletion layer at the interface of both materials [136]. The electrons will be trapped by the atmospheric oxygen resulting in an increase of the depletion layer width at the p-n junction. Thus, the increase in the concentration of adsorbed oxygen species will improve the interaction of the sensing structure with ethanol at RT. Moreover, Motsoeneng et al. obtained similar results confirming the aforementioned hypothesis [133]. They also suggested that the concentration of materials in the composite structure may have a significant effect in its sensing response.
However, the investigations on composite structures for sensing applications indicate that this topic is still in its infancy. Therefore, the combination of different materials in composite sensing structures may open new possibilities to improve their functionalities. In addition, further studies should be carried out considering the composition of composite and the concentration of materials in the structure to improve its selectivity towards a specific VOC. Furthermore, more investigations are needed to evaluate the stability of metal oxide nanomaterials, which is important for the development of sensing devices with the reproducible functional properties.

\section{Sensing systems based on $\mathrm{THz}$ spectroscopy}

Analytical spectroscopy represents a complementary approach for the detection of VOCs. A large part of these common techniques uses IR spectral regions. The spectroscopic methods include non-dispersion IR (NDIR), differential absorption LIDAR (DIAL), differential optical absorption spectroscopy (DOAS), tunable diode laser absorption spectroscopy (TDLAS), Fourier transform 
(a)

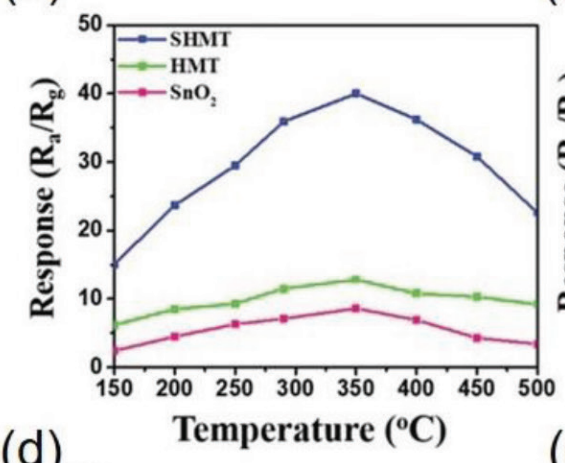

(d)

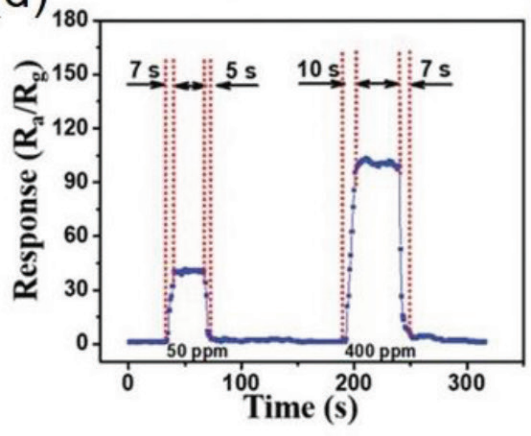

(b)

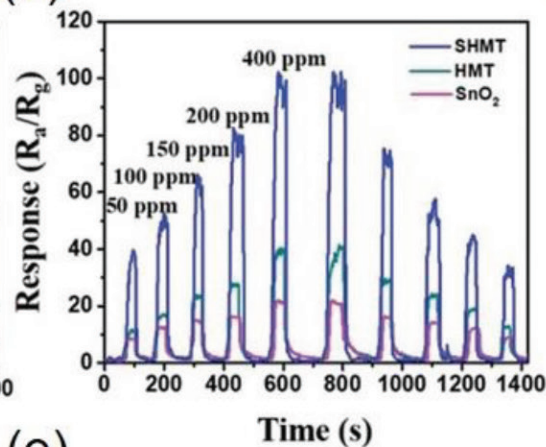

(e)

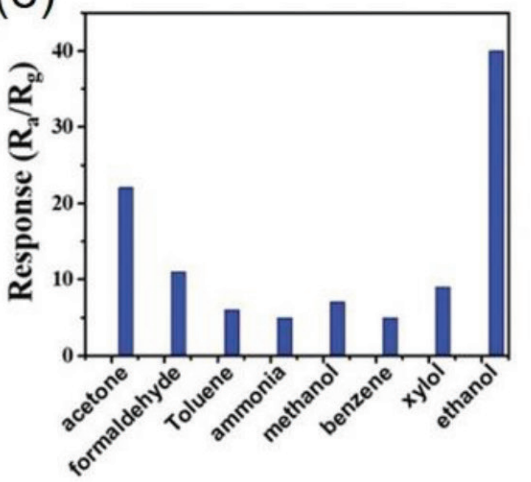

(c)

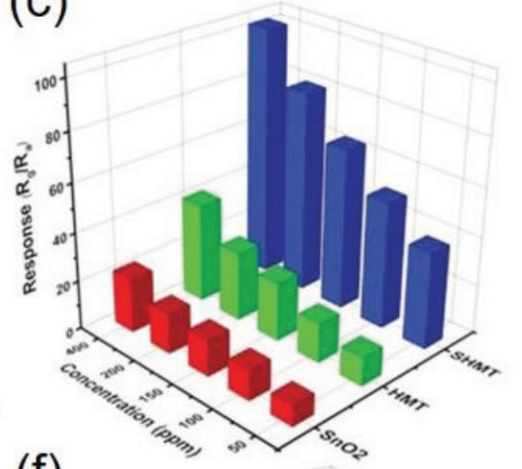

(f)

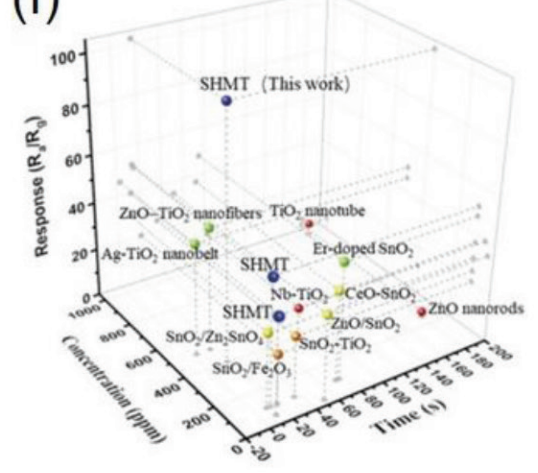

Figure 8: (a) Responses of HMT, $\mathrm{SnO}_{2} \mathrm{NCs}$, and SHMT-based sensors toward $50 \mathrm{ppm}$ ethanol at different operating temperatures $\left(150-500^{\circ} \mathrm{C}\right.$ ). (b) Response curves of gas sensors based on $\mathrm{SnO}_{2} \mathrm{NCs}, \mathrm{HMT}$, and SHMT materials toward different concentration of ethanol $(50-400 \mathrm{ppm})$ at $350^{\circ} \mathrm{C}$, (c) responses of the sensors based on $\mathrm{SnO}_{2} \mathrm{NCs}$, HMT, and SHMT sensors to ethanol vapor under different concentrations (50-400 ppm). (d) Dynamic response-recovery curve of the SHMT to 50 and $400 \mathrm{ppm}$ ethanol. (e) Responses of SHMT sensor to various gases at $50 \mathrm{ppm}$ to test the selectivity. (f) Comparison of the response and response/recovery time based on SMO sensors Reprinted with permission from Ref. [131]. Copyright 2019, John Wiley \& Sons.

infrared (FTIR) spectroscopy [81], open-path FTIR (OPFTIR) useful for measuring atmospheric gas species [140], and dual-comb spectroscopy (DCS) [141-143].

Among the aforementioned approaches, FTIR spectroscopy is largely adopted and recommended as an optical technique for the detection of VOCs showing high sensitivity, signal-to-noise ratio (SNR) and spectral resolution $[144,145]$. The LOD of the sensors based on FTIR technology strongly depends on the optical path length resulting in the detection of changes in gas concentration at ppb level [145,146]. For example, X. Zhang et al. studied the decomposition products of $\mathrm{SF}_{6}$ designing a gas cell with a 20-m-long optical path, based on the principle of White-cell and matching with FTIR [147]. Comparing the results achieved through FTIR equipped with the long gas cell and the gas chromatographic analysis, the FTIR sensitivity is able to discriminate a greater number of $\mathrm{SF}_{6}$ decomposition products than gas chromatography.

Although FTIR can be used for on-line monitoring [77,78], the gas cell and the quantitative analysis algorithm must be customized. The quantitative analysis in IR spectroscopic gas sensing is based on the relationship between the magnitude of the absorptions in the spectrum and the gas concentration [148]. Simple models, such as the single-linear-regression (SLR) and the multiple-linear-regression (MLR) can be used to evaluate the concentrations.

The accuracy of the identification of each component is crucial in multi-component gas mixtures (for example, in air quality monitoring). It may have drawbacks of low recognition rate in the extraction of useful features due to the complex pattern of spectral lines. Moreover, the inability to carry out real-time online analysis for the overlapping of absorption peaks for each gas component and $\mathrm{H}_{2} \mathrm{O}$ vapor interferences is a delicate point. Thus, different post-processing analysis methods can be adopted: library searching is useful for single spectral components and absorption peaks rarely overlapped [149]; chemometrics models and pattern recognition methods [150]. In addition, a variety of artificial neural network (ANN) algorithms are proposed for more complex FTIR spectrum identification [151,152]. For example, Yang and Griffiths encoded the spectra of five alcohols, identifying them correctly from more than 100 spectra of different compounds 
through Hopfield network [151]. Li et al. used BackPropagation Artificial Neural Network for simultaneous quantification of a mixture of methylene chloride $\left(\mathrm{CH}_{2} \mathrm{Cl}_{2}\right)$, chloroform $\left(\mathrm{CHCl}_{3}\right)$, and acetone, where strong overlaps between the main absorption peaks of three gases do not ensure the ordinary calculation of Path Integrated Concentration $[152,153]$.

The technical progress has allowed the production [104,154-163] and the coherent detection of sub-picosecond (ps) pulses of $\mathrm{THz}$ radiation $[160,164,165]$. Its potential applications span in various research fields [109,166-171], from biomedicine [108,172-174], material investigation [175-177] and particle acceleration [178-179] to environmental and security monitoring $[93,180]$. The technological availability and the high selectivity in THz region have led to an increasing interest in $\mathrm{THz}$ spectroscopy for the detection of toxic compounds [75,94-98], especially VOCs, and the validation of $\mathrm{THz}$ spectroscopy-based systems as complementary spectroscopic tools. In addition, the request for fast, non-destructive and low-cost detection and chemical identification is easily fulfilled looking at the variation of gas optical features [87-89]. Thus, $\mathrm{THz}$ spectroscopy exhibits many advantages for gas sensing applications compared to conventional IR techniques. Depending on the molecule structures, the strong rotational transitions are located at low frequencies, around 0.1-0.5 THz [181]. For example, common breath gases identify more than 1,000 absorption lines within the 0.2-0.3 THz range. In addition, methanol $\left(\mathrm{CH}_{3} \mathrm{OH}\right)$ exhibits a strong transition between $0.2-0.3 \mathrm{THz}$ with a line intensity of $8.3 \times 10^{-23} \mathrm{~cm}^{-1} /\left(\right.$ molecule $\left./ \mathrm{cm}^{2}\right)$ at 10 Pa per $1 \mathrm{~m}$ absorption length [92]. In order to perform sensing measurements, the gaseous target is generally irradiated in the $\mathrm{THz}$ range in an absorption cell at a fixed pressure while its spectral response is acquired, which gives the fingerprint feature or decay signals of the pulse [87-89].

Different systems are reported in literature: THz-TDS [182-187] and THz-FDS [188] based on photomixing [76,188], photoconductive antennas [104], and non-linear crystals [105], heterodyne detection and/or chirped-pulse [79].

Figures 9a,b report the THz-TDS absorption coefficient of acetone and $\mathrm{CH}_{3} \mathrm{OH}$ in gaseous-phase between 0.2 to $2.5 \mathrm{THz}$ with $15 \mathrm{GHz}$ spectral resolution, obtained by means of a home-made THz-TDS spectrometer at Terahertz laboratory (University of Rome, 'La Sapienza') [93,108].

They exhibit a different trend in the $\mathrm{THz}$ region. Acetone exhibits a single and broad absorption band from 0.2 to $1.2 \mathrm{THz}$ (centered at $0.562 \pm 0.015 \mathrm{THz}$ ) assigned to a convolution of many hindered rotation transitions, which is in agreement with a previous report [189]. Instead, $\mathrm{CH}_{3} \mathrm{OH}$ has many constant spaced absorption lines related to the rotational transitions. They are almost equally spaced of $50 \mathrm{GHz}$ and the most intense absorption peak is located at $2.038 \pm 0.015 \mathrm{THz}$ [189]. Thanks to the different characteristic spectral features, THz-TDS has great potentialities in identification of different gaseous substances due to their specific optical response in the $\mathrm{THz}$ region.

In gas sensing applications, a higher selectivity of THz-TDS compared to IR spectroscopy was demonstrated by examining various gases, such as acetaldehyde $\left(\mathrm{C}_{2} \mathrm{H}_{4} \mathrm{O}\right)$, acetonitrile $\left(\mathrm{C}_{2} \mathrm{H}_{3} \mathrm{~N}\right), \mathrm{NH}_{3}$, ethanol, $\mathrm{CH}_{3} \mathrm{OH}$, propionaldehyde, propionitrile $\left(\mathrm{C}_{3} \mathrm{H}_{5} \mathrm{~N}\right)$, and $\mathrm{H}_{2} \mathrm{O}$ vapor in the range between 0.03-3.9 THz [184].

The LOD for a commercial THz-TDS system is around $40 \mathrm{ppm}$ for CO [187]. This value can be optimized by specific customized THz-TDS systems. For example, it has been
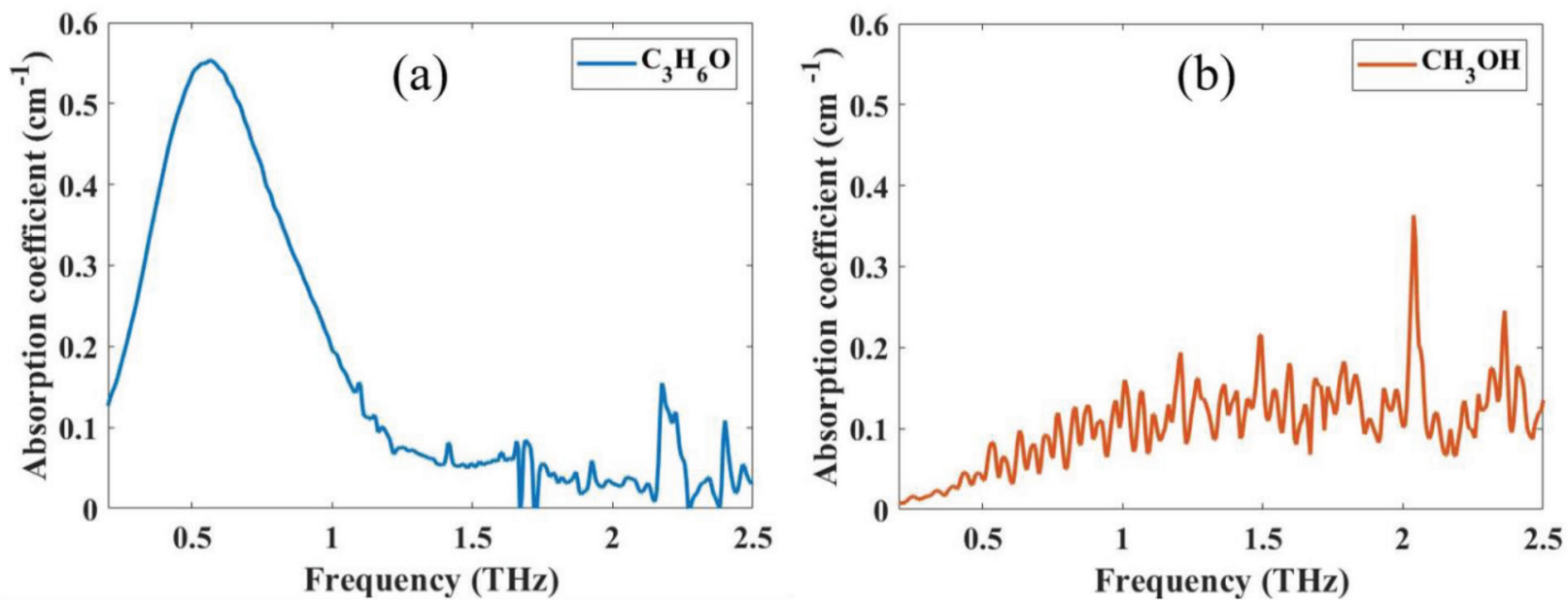

Figure 9: (a) Acetone and (b) $\mathrm{CH}_{3} \mathrm{OH}$ absorption coefficients in gaseous phase within 0.2-2.5 THz range (15 GHz spectral resolution). The measurements were performed with the THz-TDS setup at Terahertz laboratory, University of Rome 'La Sapienza' (original image). 
demonstrated that lower concentrations can be detected (less than $10 \mathrm{ppm}$ for $\mathrm{C}_{2} \mathrm{H}_{3} \mathrm{~N}, \mathrm{CO}, \mathrm{CH}_{3} \mathrm{OH}$, and $\mathrm{H}_{2} \mathrm{O}$ ) with 50-60 dB SNR on a single measurement [185].

Medvedev et al. acquired spectra of triflouromethane $\left(\mathrm{CHF}_{3}\right)$, difluoromethane $\left(\mathrm{CH}_{2} \mathrm{~F}_{2}\right)$, iodoform $\left(\mathrm{CHI}_{3}\right)$, and carbon disulfide $\left(\mathrm{CS}_{2}\right)$ using a THz-TDS scheme [183]. They proposed a quantification of the gas complex rotational spectrum at a rate of 105 spectral resolution elements/second with a high SNR. In addition, they analyzed gas mixtures spectra in combination with powerful signal processing.

Unlike IR spectroscopy, where the aerosol scattering reduces the performance of the detection system, $\mathrm{THz}$ spectroscopy may provide dynamic analysis of molecular gases for environmental monitoring providing spectral information of rotational transitions without aerosol scattering effect. Hsieh et al. performed dynamic analysis of gas-phase $\mathrm{C}_{2} \mathrm{H}_{3} \mathrm{~N}$ in presence of smoke at atmospheric pressure using a fiber-based asynchronousoptical-sampling THz-TDS spectrometer with a spectral resolution of $1 \mathrm{GHz}$ [186]. Without the influence of scattering and/or absorption by the smoke, many rotational transitions were spectrally resolved at a measurement rate of $1 \mathrm{~Hz}$ from 0.1 to $1 \mathrm{THz}$. The transparency of optically opaque medium to $\mathrm{THz}$ radiation, as demonstrated for smoke, can be exploited to identify the presence of reaction products of industrial processes. Hydrogen cyanide ( $\mathrm{HCN}$ ) and $\mathrm{H}_{2} \mathrm{O}$ molecules generated by the combustion of a urethane foam block can be detected [190], suggesting possible applications related to the detection of hazardous gases in remote locations [191]. The experiment was conducted at a low concentration of dinitrogen monoxide $\left(\mathrm{N}_{2} \mathrm{O}, 25 \%\right.$ in air) with a gas cell 1-m-long. The possibility of remote detection of nitrous compounds $\left(\mathrm{N}_{\mathrm{x}} \mathrm{O}_{\mathrm{y}}\right.$ ) confirms the capability of THz-TDS for the applications in monitoring systems, which may be also exploited to identify explosives and toxic pollutants in the atmosphere [191].

The remote sensing in the atmosphere is strictly related to the propagation of broadband coherent $\mathrm{THz}$ radiation and depends on various humidity levels [192]. The ultrashort THz pulses propagation in a 100-m-long path at $10 \% \mathrm{RH}$ was extensively investigated, as well as the absorption study for $\mathrm{THz}$ radiation $(0.2-2 \mathrm{THz})$, generated by optoelectronic antennas in the presence of $\mathrm{H}_{2} \mathrm{O}$ vapor in a 6.2-m-long path [193,194]. Generally, high THz power with strong electric fields of several hundreds of $\mathrm{kVcm}^{-1}$ is advantageous due to the excellent response to the target gas offering new perspectives to increase the open space distances in remote sensing $[164,195]$. The portability of $\mathrm{THz}$ spectrometer for real-time gas analysis was demonstrated by Demers and Garet that mounted the device to a consumer drone UAV [196].

Recently, optical frequency combs have combined with the photomixing technique leading to the higher frequency accuracy, stability, and resolution at some expense of bandwidth. The aforementioned improvements have been demonstrated in the detection of methanol vapor at various atmosphere concentrations using a fiber-based photomixing $\mathrm{THz}$ spectrometer with bandwidth between 50-1200 GHz [197]. Due to the achieved high frequency resolution, Zhang et al. resolved absorption spectrum for methanol and assigned the absorption peaks to energy levels from $\mathrm{J}=7$ to $\mathrm{J}=21$ with $\mathrm{J}$ total angular momentum quantum. Meanwhile, they performed a post-processing approach to remove the $\mathrm{H}_{2} \mathrm{O}$ vapor contribution [197].

Hsieh et al. performed photomixing THz synthesizer phase-locked to dual optical frequency combs demonstrating efficacy of the $\mathrm{THz}$ synthesizer in gas sensing and operating with a gas cell at a pressure of $20 \mathrm{~Pa}$ [188]. THz-FDS characterization of gas-phase $\mathrm{C}_{2} \mathrm{H}_{3} \mathrm{~N}$ and its isotope $\left(\mathrm{CH}_{3}{ }^{13} \mathrm{CN}\right)$ was carried out in the frequency range of $0.600-0.720 \mathrm{THz}$ and their rotational transitions were assigned with a frequency resolution of $520 \mathrm{kHz}$ [194].

Nevertheless, to improve the detection range of gases from ppm to ppb level, spectroscopic systems should be equipped with a chamber, a long folded multipass gas cell [198], a cryo/sorbent pre-concentration system and a heating apparatus [75]. Hepp et al. used the FDS system equipped with a multipass cell and evacuated to 1 mbar to detect trace amounts of gases released in a blaze or a chemical spill in an industrial facility. The achieved LOD of the system was in the range of $20 \mathrm{ppm}$ for $\mathrm{NH}_{3}$ and $100 \mathrm{ppm}$ for sulfur dioxide $\left(\mathrm{SO}_{2}\right)$ [198]. Hence, the application of a preconcentration enhances the detection performance and reduces the LOD.

Neese et al. developed a system based on submillimeter/THz (mm/THz) technology that sorbents to capitalize on the small sample requirements of the spectroscopic technique and computational algorithm approach in order to use the information contained in the complex rotational fingerprints [75]. In the spectral region from 210 to $270 \mathrm{GHz}, 14$ mixtures of gases were characterized including hydrochloric acid $(\mathrm{HCl}), \mathrm{NH}_{3}$, acetylene $\left(\mathrm{C}_{2} \mathrm{H}_{2}\right)$, CO, nitrogen oxide (NO), and cyanogen chloride (ClCN), confined in a cell coupled with the pre-concentration system. The LOD for deuterated $\mathrm{C}_{2} \mathrm{D}_{3} \mathrm{~N}$ was $69 \mathrm{ppt}$.

$\mathrm{THz}$ custom-designed systems were used to identify alcohol and several biomarker gases in human exhaled breath [79,199-201]. In particular, Rothbart et al. employed a specially designed gas cell reported in Figure 10 [201]. The probe beam traverses it multiple times (11 passes) in 


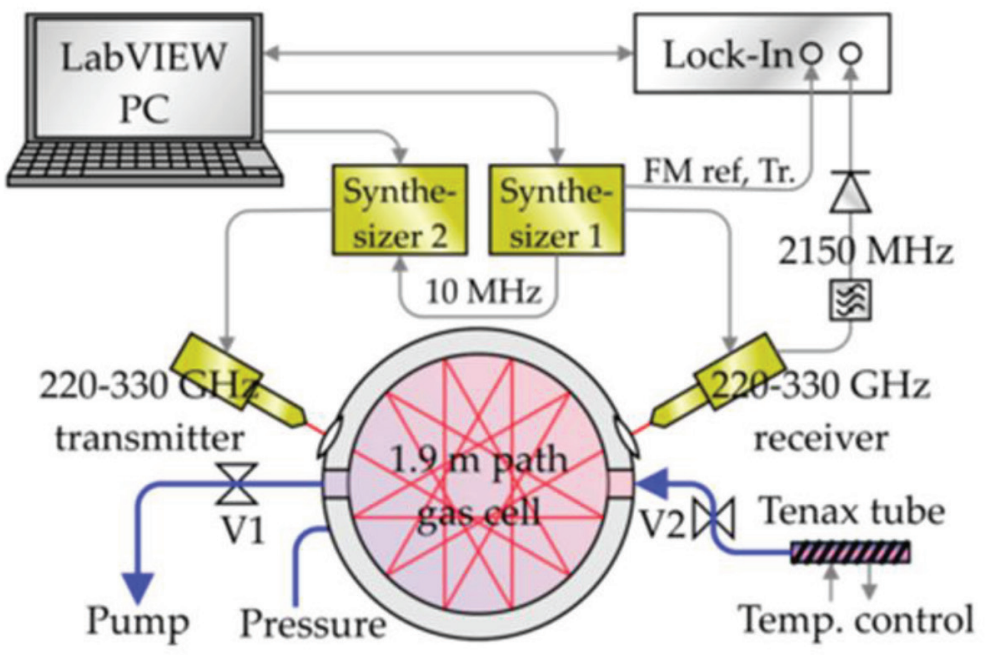

Figure 10: Setup of the $\mathrm{mm} / \mathrm{THz}$ gas spectrometer for breath analysis. Reprinted from Ref. [201].

order to extend the interaction length with the contained gas, thus increasing the absorption signals. They detected 21 gases in the frequency range from 220 to $330 \mathrm{GHz}$ observing a clear distinction between smoker and nonsmoker samples. Figure 11 reports the line shape for the smoker's sample.

Other methods have been proposed to increase the minimum detectable gas concentration, such as $\mathrm{THz}$ resonance field in a photonic crystal [202-206] and plasmonic $[207,208]$ or a waveguide device $[209,210]$. The last two methods, in particular, are sensitive to slight variations of the refractive index. For example, a dielectric pipe waveguide can be successfully validated as THz refractive-index sensor for powder and liquid-vapor sensing. The proven LOD is approximately $1.6 \mathrm{nmol} / \mathrm{mm}^{3}$ [208] and the highest sensitivity was observed at around $22.2 \mathrm{GHz} /$ refractiveindex-unit, which is comparable to high-performance $\mathrm{THz}$ molecular sensor [208].

1-dimensional photonic crystal cavity based on silicon slabs [204] and 2-dimensional photonic crystal resonators [205] based on pillar arrays were proposed for non-specific gas sensing in the $\mathrm{THz}$ frequency range. In particular, Chen et al. proposed a resonator structure that has a highquality factor and is able to detect slight changes in the refractive index [204]. The developed system even detected a $6 \%$ variation in the concentration of the analyte [204].

Although this $\mathrm{THz}$ gas sensor is relatively compact, portable, and low power consumption, its short interaction length essentially leads to no-excessive sensitivity and selectivity and no-high quality factor. However, precisely designed ultrahigh quality factor $\mathrm{THz}$ disc microresonators allow the implementation on compact and highly sensitive THz-gas sensing spectrometers [211] that monitor a change in Q-factor under variation of the gas concentration in the resonator's environment. The comparison of two curves reported in Figure 12 shows the broadening (lower Q-factor) of the interesting resonances with absorption of $\mathrm{H}_{2} \mathrm{O}$ vapor. In this proof-of-concept demonstration, less than $4 \mathrm{ppm}$ of $\mathrm{H}_{2} \mathrm{O}$ vapor at atmospheric pressure was readily detected.

Different porous materials [212-217], such as porous silicon (PS) [212], porous zinc oxide [214], carbon nanotubes [215], mesoporous photonic crystals [213,216], and polymers [217] have been extensively used in optical gas sensors for highly sensitive detection of ultrasmall quantities of analytes. Porous and sponge-like structures can adsorb large amounts of gas molecules inside the pores modifying the original optical properties of the sensing system. In particular, the increase in the concentration of gas molecules inside the nanopores induces evident changes in the refractive index resulting in the apparent spectral shifts of interference fringes. The resonant peaks or dips were significantly enhanced [212]. The interaction length between the electromagnetic waves and analytes can also be easily decreased to obtain a compact size for the sensing unit. Meanwhile, the multilayer stack of porous materials enables the reduction of the sensor size and increases the amount of adsorbed gas molecules. Porous materials can be fabricated with different configurations, such as multilayer-stacked photonic crystal devices, periodically colloidal beads and as the membrane for gas sensing [212]. The application of porous polymers, mostly transparent in the $\mathrm{THz}$ region, is an effective strategy to develop optical sensing systems. Stacking multiple layers of flexible plastic porous membranes, with different porosities, can be used to distinguish various VOCs. Moreover, the changes in the concentration of VOCs can be detected analyzing the $\mathrm{THz}$ wave attenuation and the refractive 


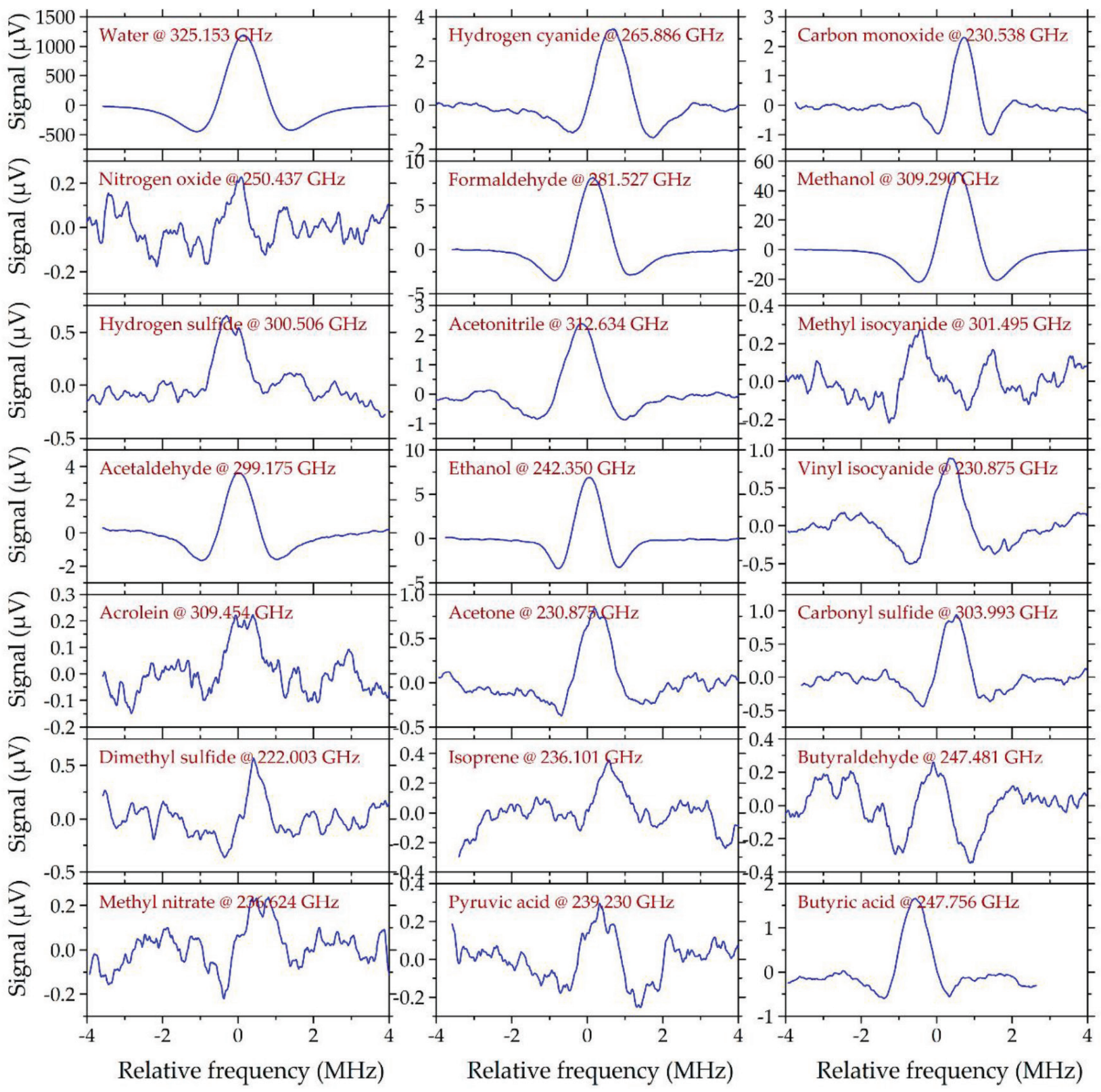

Figure 11: Line scans of the smoker's sample with the largest signal for each molecular species. Reprinted from Ref. [201].

index variation induced by the adsorption of analyte in the microporous structure. For example, You et al. carried out an experiment, where $17 \mathrm{ppm}$ of acetone vapor was successfully detected at RT and ambient atmosphere [217]. Furthermore, they estimated the LOD from the linear fitting curve, which was $7 \mathrm{ppm}$ (corresponds to a molecular density of $125 \mathrm{pmol} / \mathrm{mm}^{3}$ ). The main schemes and sensing parameters for the detection of VOCs using THz spectroscopy are reported in Table 2.

Overall, the $\mathrm{THz}$ technology offers an alternative experimental approach for the gas sensing recognition. The specific and unique roto-vibrational transitions in
THz spectral range, the noninflammability and no effects from aerosol scattering ensure its application in various monitoring fields.

However, $\mathrm{THz}$ radiation strongly interacts with polar molecules such as $\mathrm{H}_{2} \mathrm{O}[93,106,108]$. This fact limits its application in real atmosphere due to the strong attenuation of $\mathrm{THz}$ radiation by the atmospheric $\mathrm{H}_{2} \mathrm{O}$ vapor. To overcome this issue, two different approaches have been suggested: (i) application of a chamber to isolate the target gas from the outside atmosphere; (ii) application of a strong electric field using air plasma-based $\mathrm{THz}$ generation methods. In presence of gaseous mixtures, 
(a)
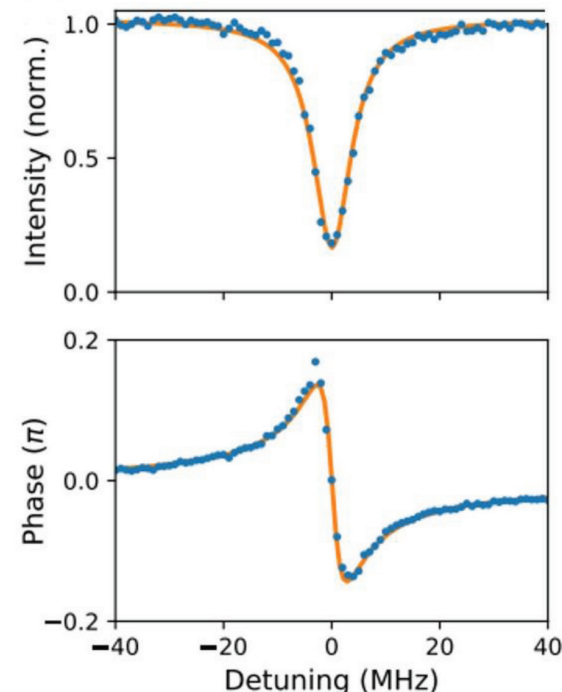

(b)
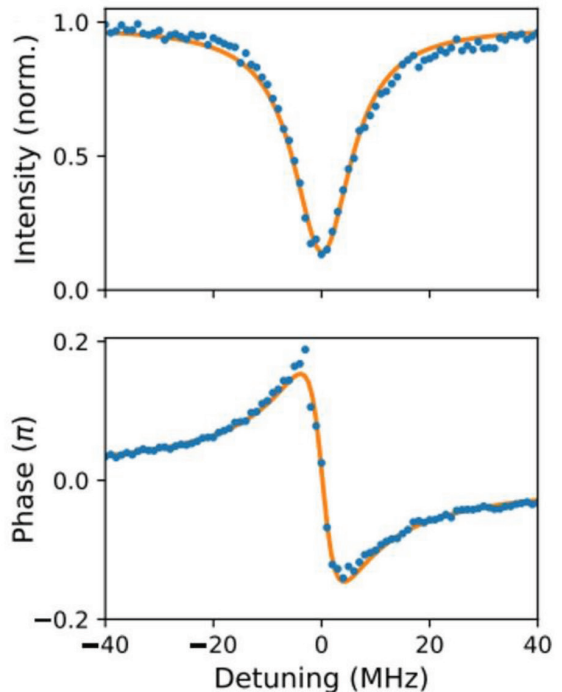

Figure 12: The measured intensity and phase profiles (blue dots) of the resonance at $0.5561 \mathrm{THz}$ at (a) $7 \mathrm{ppm}$ per volume and (b) $120 \mathrm{ppm}$ per volume $\mathrm{H}_{2} \mathrm{O}$ vapor concentrations. Reprinted from Ref. [211].

Table 2: Sensing parameters of schemes and devices based on THz spectroscopy for the detection of VOCs

\begin{tabular}{|c|c|c|c|c|c|}
\hline Technique & Spectral range & Spectral resolution & Analyte & LOD (ppm) & Ref. \\
\hline THz-TDS & $0.1-2.5 \mathrm{THz}$ & $1.5 \mathrm{GHz}$ & $\mathrm{C}_{2} \mathrm{H}_{3} \mathrm{~N}, \mathrm{CO}, \mathrm{CH}_{3} \mathrm{OH}, \mathrm{H}_{2} \mathrm{O}$ & $<10$ & {$[185]$} \\
\hline THz-FDS & $0.5-1.5 \mathrm{THz}$ & $7 \mathrm{MHz}$ & $\mathrm{NH}_{3} ; 100, \mathrm{SO}_{2}$ & 20 & [198] \\
\hline THz-TDS & 0.03-3.9 THz & $7 \mathrm{GHz}$ & $\begin{array}{c}\mathrm{C}_{2} \mathrm{H}_{4} \mathrm{O}, \mathrm{NH}_{3}, \mathrm{C}_{2} \mathrm{H}_{3} \mathrm{~N}, \mathrm{C}_{2} \mathrm{H}_{5} \mathrm{OH}, \mathrm{H}_{2} \mathrm{O} \\
\mathrm{C}_{3} \mathrm{H}_{6} \mathrm{O}, \mathrm{CH}_{3} \mathrm{OH}, \mathrm{C}_{3} \mathrm{H}_{5} \mathrm{~N}\end{array}$ & 1 & [184] \\
\hline Fiber THz-TDS & $0.2-1 \mathrm{THz}$ & $1 \mathrm{GHz}$ & $\mathrm{CH}_{3} \mathrm{CN}$ & 36 & [186] \\
\hline THz-FDS & 0.6-0.72 THz & $5 \mathrm{MHz}$ & $\mathrm{CH}_{3} \mathrm{CN}, \mathrm{CH}_{3}{ }^{13} \mathrm{CN}$ & - & [188] \\
\hline THz-TDS & $0.1-1.8 \mathrm{THz}$ & $\sim 15 \mathrm{GHz}$ & $\mathrm{H}_{2} \mathrm{O}, \mathrm{H}_{2} \mathrm{~S}$ & - & [218] \\
\hline THz-TDS & $238-252 \mathrm{GHz}$ & $500 \mathrm{kHz}$ & $\begin{array}{c}\mathrm{C}_{2} \mathrm{H}_{4} \mathrm{O}, \mathrm{CH}_{3} \mathrm{OH}, \mathrm{C}_{3} \mathrm{H}_{8} \mathrm{O}, \mathrm{CH}_{3} \mathrm{OD}, \mathrm{C}_{3} \mathrm{H}_{6} \mathrm{O} \\
\mathrm{CH}_{3} \mathrm{CN}, \mathrm{C}_{2} \mathrm{H}_{6} \mathrm{O}\end{array}$ & - & [219] \\
\hline THz-TDS & $119.1-119.5 \mathrm{~cm}^{-1}$ & $0.004 \mathrm{~cm}^{-1}$ & $(\mathrm{HCN})_{2}$ & - & [220] \\
\hline THz-TDS + concentrator & $0.5-6.2 \mathrm{THz}$ & $30 \mathrm{GHz}$ & $\mathrm{CO}_{2}, \mathrm{C} 2 \mathrm{H} 6, \mathrm{C}_{4} \mathrm{H}_{10}$ & - & [221] \\
\hline THz-TDS & $2 \mathrm{THz}$ & - & $\mathrm{CO}_{2}$ & - & [196] \\
\hline THz-TDS & $246.8-261.2 \mathrm{GHz}$ & $3 \mathrm{GHz}$ & $\mathrm{COS}, \mathrm{CH}_{3} \mathrm{~F}, \mathrm{CH}_{2} \mathrm{~F}_{2}, \mathrm{CH}_{3} \mathrm{I}$ & - & [183] \\
\hline Continuous wave $\mathrm{THz}$ & $1026-1028 \mathrm{GHz}$ & $50 \mathrm{kHz}$ & $\mathrm{H}_{2}{ }^{32} \mathrm{~S}, \mathrm{H}_{2}{ }^{33} \mathrm{~S}$ & 20 & [222] \\
\hline THz-TDS & $0.1-2 \mathrm{THz}$ & $37.5 \mathrm{GHz}$ & $\mathrm{CO}, \mathrm{NO}$ & - & [89] \\
\hline SMM & $210-270 \mathrm{GHz}$ & $0.5 \mathrm{GHz}$ & $\begin{array}{c}\mathrm{HCN}, \mathrm{H}_{3} \mathrm{CN}, \mathrm{C}_{2} \mathrm{H}_{4} \mathrm{Cl}_{2}, \mathrm{CH}_{3} \mathrm{CN}, \mathrm{C}_{2} \mathrm{H}_{3} \mathrm{CN}, \\
\mathrm{C}_{2} \mathrm{H}_{5} \mathrm{CN}_{2} \mathrm{C}_{2} \mathrm{H}_{3} \mathrm{~F}\end{array}$ & In ppt level & [97] \\
\hline Chirped pulse THz spectroscopy & $230-620 \mathrm{GHz}$ & - & $\mathrm{CH}_{3} \mathrm{OH}, \mathrm{N}_{2} \mathrm{O}, \mathrm{COS}, \mathrm{C}_{2} \mathrm{H}_{5} \mathrm{OH}, \mathrm{C}_{3} \mathrm{H}_{6} \mathrm{O}, \mathrm{H}_{2} \mathrm{O}$ & $2-8000 \mathrm{ppb}$ & {$[88]$} \\
\hline THz-TDS & $0.1-3 \mathrm{THz}$ & $7.3 \mathrm{GHz}$ & $\mathrm{CH}_{3} \mathrm{OH}, \mathrm{C}_{3} \mathrm{H}_{6} \mathrm{O}$ & - & [189] \\
\hline THz-FDS & $200-500 \mathrm{GHz}$ & $0.5 \mathrm{GHz}$ & $\mathrm{HCN}, \mathrm{H}_{2} \mathrm{O}$ & 640 & [190] \\
\hline THz-TDS & $0.2-2 \mathrm{THz}$ & $6.1 \mathrm{GHz}$ & $\mathrm{H}_{2} \mathrm{O}$ & - & [194] \\
\hline THz-TDS & $0.2-3 \mathrm{THz}$ & $7 \mathrm{GHz}$ & $\mathrm{CH}_{3} \mathrm{CN}$ & - & [195] \\
\hline
\end{tabular}


partial overlapping of absorption lines shows complex absorption spectra making difficult the recognition of each compound. In this case, post-processing methods may be carried out taking the advantage of the network analysis, machine learning, and principal components analysis algorithms. Some preliminary research findings have been reported based on the studies of human breath. Meanwhile, gas concentrators have been suggested for the detection and identification of ultra-small concentrations of VOCs. The application of metamaterials, plasmonic, and resonant structures may extend the use of the natural dielectric response in the long-wavelength regime and overcome the optical resolution limit.

Alternatively, microporous structures for the adsorption of the analyte can be used as gas filters. Interrogating these structures with $\mathrm{THz}$ wave, as well as the analysis of the $\mathrm{THz}$ wave attenuation and the refractive index variation will improve the efficiency of the detection and quantification of VOCs.

\section{Conclusions and outlook}

The increasing number of experimental studies on the development of new strategies and advanced technologies for the detection of VOCs confirms the relevance of the systems for monitoring of air quality and human health status. Meanwhile, in the development of highperformance detection systems, an effective methodology and planning are required to successfully achieve the expected objectives. Therefore, the application field can play a significant effect on the design and fabrication of sensing systems. Herein, we have discussed two different types of sensors that have been used for the manufacturing of monitoring systems.

Chemiresistive sensors based on metal oxide materials take advantage of the fact that their conductance changes with the concentration of VOCs. Moreover, the size reduction of oxide materials to the nanoscale will dramatically change the performance of chemical gas sensors. Overall, the research studies indicate that metal oxide nanomaterials with different shapes and morphologies are sensitive towards a wide range of VOCs. In the meantime, the crystal structure, shape, and size of metal oxides affect their response towards VOCs. The response and selectivity of chemiresistive sensors can be enhanced by doping and functionalization with different materials. In particular, dopant materials with higher oxidation states substitute the atoms of the metal oxides and maintain the same oxidation state of the structure increasing its electrical conductivity, which is beneficial to read out the conductance change of the sensor using cost-effective and small size electrical devices. Furthermore, the dopants may introduce crystal defects in the metal oxide nanomaterial resulting in the formation of oxygen vacancies and enhancing the adsorption of VOCs on the sensing structure.

Noble metals with their catalytic features can affect the dissociation of atmospheric $\mathrm{O}_{2}$ and increase the concentration of adsorption sites on the oxide material activating the surface reactions between the VOCs and sensors. The electronic sensitization of noble metals plays an important role in the improvement of the response of metal oxides due to the formation of the potential barrier at the grain boundaries increasing the width of the depletion layer at the interface between the sensing structure and catalyst. Thus, the charge carriers are released more easily from the surface reactions at the catalyst/metal oxide interface to the conduction band improving the functionalities of chemiresistive sensors. As a result of these studies, the response of the metal oxides towards VOCs has been improved at the relatively low operating temperatures, which reduces the power consumption of the final sensing device. However, it is important to distinguish each VOC in the presence of more complex mixtures, and therefore the enhancement of the selectivity of chemical gas sensors remains a challenging issue.

In this regard, the fabrication of chemiresistive sensors based on metal oxide nanocomposites has proven a very promising strategy to improve their response and selectivity. The studies indicate that the coupling of $\mathrm{p}$ - and n-type metal oxides in a composite structure may open a new avenue for the preparation of emerging functional nanomaterials and their integration in detection systems. In this case, the formation of a p-n heterojunction and its modulation due to the adsorption/desorption processes of VOCs may have a significant effect on the sensing performance of the composite material. However, this is a relatively new strategy and a deeper understanding of the contribution of each material in the sensing properties of gas sensors is needed considering different metal oxides and concentrations. Meanwhile, the stability of the functional properties of metal oxides should be tested for longer periods (more than a few months) for their integration in monitoring systems. Unfortunately, sometimes the LOD of the fabricated sensors was not considered in the investigations, which makes difficulties to compare the sensing parameters of different structures and compositions.

Currently, the field of vibrational spectroscopy is expanding extensively. In particular, optical gas sensors 
based on $\mathrm{THz}$ spectroscopy take advantage of the fact that many gases show specific roto-vibrational transitions in the THz spectral region. Compared to the common mid-IR region, polar gases have relatively unique set of absorption lines in this spectral range facilitating their selective recognition. Various optical schemes have been reported in the research studies. The capability of THz spectroscopy for the detection and identification of VOCs with a wide range of concentrations and low LOD has been demonstrated. Furthermore, the developed cost-effective devices show easy availability and portability with low absorption loss. Considering the advantages of $\mathrm{THz}$ radiation (noninflammability and no effects from aerosol scattering), $\mathrm{THz}$ sensors are suitable for the detection of VOCs at ambient conditions and for applications in human breath analysis and environmental/occupational monitoring.

However, THz waves show strong absorption due to humidity, limiting the functionality of the sensing devices, especially in atmospheric environmental monitoring. The limitations can be overcome by isolating the gas target from the outside atmosphere and/or by applying strong THz electric fields achieved with air plasma-based $\mathrm{THz}$ generation methods. The latter is more effective due to its strong response to the target VOC through the high THz power. However, this technology is in its infancy and further studies are required.

Furthermore, the advances in computational analysis including the network analysis, machine learning, and principal components analysis algorithms led to the development of various post-processing methods. In presence of gaseous mixtures, where the recognition of each component is difficult due to the partial overlapping of absorption lines, the computational approaches may ensure valid support in the spectra interpretation. Meanwhile, gas nano- or micro-structured concentrators have been suggested for the treatment of ultrasmall concentrations of VOCs.

Definitely, THz spectroscopy is a relatively novel optical sensing system and it has room for development in the near future. The application of new materials and technological advances in the field of $\mathrm{THz}$ radiation will enhance the gas sensing performance of $\mathrm{THz}$ optical sensors offering new possibilities for the fabrication of monitoring systems with low LOD.

Research funding: This work was partially funded by the NATO Science for Peace and Security Programme under grant No. G5634 "Advanced Electro-Optical Chemical Sensors" and by MIUR "Smart Cities and Communities and social innovation" project titled "SWaRM Net/Smart Water Resource Management - Networks”. This research was also supported through the bilateral cooperation agreement between Italy and China of the Italian Ministry of Foreign Affairs and of the International Cooperation (MAECI) in the framework of the project of major relevance No. PGR00772.

Author contributions: Vardan Galstyan: conceptualization, supervision, visualization, writing - original draft, writing - review and editing; Annalisa D'Arco: conceptualization, investigation, resources, writing - original draft, writing - review and editing; Marta Di Fabrizio: investigation, formal analysis, visualization, writing - original draft; writing - review and editing; Nicola Poli: methodology, resources, investigation, writing - original draft, writing - review and editing; Stefano Lupi: funding acquisition, supervision, writing - original draft, writing - review and editing; Elisabetta Comini: funding acquisition, project administration, writing - original draft, writing review and editing.

Conflict of interest: Authors state no conflict of interest.

\section{References}

[1] Khan Fl, Ghoshal AK. Removal of Volatile Organic Compounds from polluted air. J Loss Prev Process Ind. 2000;13(6):527-45.

[2] Lee SC, Chiu MY, Ho KF, Zou SC, Wang X. Volatile organic compounds (VOCs) in urban atmosphere of Hong Kong. Chemosphere. 2002;48(3):375-82.

[3] Liu Y, Shao M, Fu L, Lu S, Zeng L, Tang D. Source profiles of volatile organic compounds (VOCs) measured in China: Part I. Atmos Environ. 2008;42(25):6247-60.

[4] Al-Douseri FM, Chen Y, Zhang XC. THz wave sensing for petroleum industrial applications. Int J Infrared Millimeter Waves. 2007;27(4):481-503.

[5] He Z, Wang X, Ling Z, Zhao J, Guo H, Shao M, et al. Contributions of different anthropogenic volatile organic compound sources to ozone formation at a receptor site in the Pearl River Delta region and its policy implications. Atmos Chem Phys. 2019;19(13):8801-16.

[6] Salthammer T. Very volatile organic compounds: an understudied class of indoor air pollutants. Indoor Air. 2016;26(1):25-38.

[7] Al-Dabbous AN, Khan AR, Al-Tamimi SA, Shalash M, Bajoga $A D$, Malek MJ. Oxides of carbon, particulate matters and volatile organic compounds impact on indoor air quality during waterpipe smoking. Int J Environ Sci Te. 2019;16(6):2849-54.

[8] Rizk M, Guo FF, Verriele M, Ward M, Dusanter S, Blond N, et al. Impact of material emissions and sorption of volatile organic compounds on indoor air quality in a low energy building: Field measurements and modeling. Indoor Air. 2018;28(6):924-35.

[9] Schultz MG, Akimoto H, Bottenheim J, Buchmann B, Galbally IE, Gilge S, et al. The Global Atmosphere Watch reactive gases measurement network. Elem Sci Anth. 2015;3:000067. 
[10] Gentner DR, Jathar SH, Gordon TD, Bahreini R, Day DA, El Haddad I, et al. Review of Urban Secondary Organic Aerosol Formation from Gasoline and Diesel Motor Vehicle Emissions. Environ Sci Technol. 2017;51(3):1074-93.

[11] Nesheva D, Babeva T, Vasileva M, Valdez-Salas B, Dzhurkov V, Grujić-Brojčin MU, et al. Phase characterization and ethanol adsorption in $\mathrm{TiO}_{2}$ nanotubes anodically grown on $\mathrm{Ti}_{6} \mathrm{Al}_{4} \mathrm{~V}$ alloy substrates. J Alloys Compds. 2019;798:394-402.

[12] Zhang R, Hummelgård M, Ljunggren J, Olin H. Gold and ZnO-Based Metal-Semiconductor Network for Highly Sensitive Room-Temperature Gas Sensing. Sensors. 2019; 19(18):3815.

[13] Hermawan A, Zhang B, Taufik A, Asakura Y, Hasegawa $\mathrm{T}$, Zhu J, et al. CuO Nanoparticles $/ \mathrm{Ti}_{3} \mathrm{C}_{2} \mathrm{~T}_{\mathrm{x}}$ MXene Hybrid Nanocomposites for Detection of Toluene Gas. ACS Appl Nano Mater. 2020;3(5):4755-66.

[14] Tian M, Miao J, Cheng P, Mu H, Tu J, Sun J. Layer-by-layer nanocomposites consisting of $\mathrm{CO}_{3} \mathrm{O}_{4}$ and reduced graphene ( $\mathrm{rGO}$ ) nanosheets for high selectivity ethanol gas sensors. Appl Surf Sci. 2019;479:601-7.

[15] Aroutiounian VM. Gas Nanosensors Made from Semiconductor Metal Oxides. J Contemp Phys-Arme+. 2019;54(4):356-67.

[16] Kanmani R, Zainuddin NAM, Rusdi MFM, Harun SW, Ahmed $\mathrm{K}$, Amiri IS, et al. Effects of $\mathrm{TiO}_{2}$ on the performance of silver coated on side-polished optical fiber for alcohol sensing applications. Opt Fiber Technol. 2019;50:183-7.

[17] Chen Y, Li X, Li X, Wang J, Tang Z. UV activated hollow ZnO microspheres for selective ethanol sensors at low temperatures. Sensor Actuat B-Chem. 2016;232:158-64.

[18] Bhowmik B, Bhattacharyya P. Highly stable low temperature alcohol sensor based on hydrothermally grown tetragonal titania nanorods. RSC Adv. 2015;5(100):82159-68.

[19] Mascini M, Gaggiotti S, Della Pelle F, Di Natale C, Qakala S, Iwuoha E, et al. Peptide Modified ZnO Nanoparticles as Gas Sensors Array for Volatile Organic Compounds (VOCs). Front Chem. 2018;6(105):6:105.

[20] Bagheri M, Khodadadi AA, Mahjoub AR, Mortazavi Y. Gallia$\mathrm{ZnO}$ nanohybrid sensors with dramatically higher sensitivity to ethanol in presence of $\mathrm{CO}$, methane and VOCs. Sensor Actuat B-Chem. 2016;223:576-85.

[21] Seekaew Y, Wisitsoraat A, Phokharatkul D, Wongchoosuk C. Room temperature toluene gas sensor based on $\mathrm{TiO}_{2}$ nanoparticles decorated 3D graphene-carbon nanotube nanostructures. Sensor Actuat B-Chem. 2019;279:69-78.

[22] Choudhury SP, Feng Z, Gao C, Ma X, Zhan J, Jia F. BN quantum dots decorated $\mathrm{ZnO}$ nanoplates sensor for enhanced detection of BTEX gases. J Alloys Compd. 2020;815:152376.

[23] Sberveglieri V. Validation of Parmigiano Reggiano Cheese Aroma Authenticity, Categorized through the Use of an Array of Semiconductors Nanowire Device (S3). Materials. 2016;9(2):81.

[24] Madou MJ, Morrison SR. Thin-film gas sensors. In Chemical Sensing with Solid State Devices; Madou, M.J., Morrison, S.R., Editors. San Diego: Academic Press; 1989,10,419-35.

[25] Galstyan V, Comini E, Ponzoni A, Sberveglieri V, Sberveglieri G. ZnO Quasi-1D Nanostructures: Synthesis, Modeling, and Properties for Applications in Conductometric Chemical Sensors. Chemosensors. 2016;4(2):6.
[26] Yang L, Zhou X, Song L, Wang Y, Wu X, Han N, et al. Noble Metal/Tin Dioxide Hierarchical Hollow Spheres for LowConcentration Breath Methane Sensing. ACS Appl Nano Mater. 2018;1(11):6327-36.

[27] Fioravanti A, Carotta MC. Year 2020: A Snapshot of the Last Progress in Flexible Printed Gas Sensors. Appl Sci. 2020;10(5):1741.

[28] Silina YE, Gernaey KV, Semenova D, latsunskyi I. Application of organic-inorganic hybrids in chemical analysis, bio- and environmental monitoring. Appl Sci. 2020;10(4):1458.

[29] Pan W, Zhang Y, Zhang D. Self-assembly fabrication of titanium dioxide nanospheres-decorated tungsten diselenide hexagonal nanosheets for ethanol gas sensing application. Appl Surf Sci. 2020;527:146781.

[30] Amiri V, Roshan H, Mirzaei A, Neri G, Ayesh Al. Nanostructured Metal Oxide-Based Acetone Gas Sensors: A Review. Sensors. 2020;20(11):3096.

[31] Galstyan V. "Quantum dots: Perspectives in nextgeneration chemical gas sensors" - A review. Anal Chim Acta. 2021;238192, DOI: 10.1016/j.aca.2020.12.067.

[32] Madou MJ, Morrison SR. Solid/gas interfaces. In Chemical Sensing with Solid State Devices; Madou, M.J., Morrison, S.R., Editors. San Diego: Academic Press; 1989;3,67-104.

[33] Zhang L, Tong R, Ge W, Guo R, Shirsath SE, Zhu J. Facile one-step hydrothermal synthesis of $\mathrm{SnO}_{2}$ microspheres with oxygen vacancies for superior ethanol sensor. J Alloys Compd. 2020;814:152266.

[34] Wang Z, Zhang R, Gu F, Han D. Facile synthesis of $\ln _{2} \mathrm{O}_{3}$ nanoparticles with high response to formaldehyde at low temperature. International J Appl Ceram Technol. 2019;16(4):1570-80.

[35] Zhu Z, Zheng L, Zheng S, Chen J, Xing X, Feng D, et al. Multichannel pathway-enriched mesoporous $\mathrm{NiO}$ nanocuboids for the highly sensitive and selective detection of 3-hydroxy-2-butanone biomarkers. J Mater Chem A. 2019;7(17):10456-63.

[36] Zhao S, Shen Y, Yan X, Zhou P, Yin Y, Lu R, et al. Complexsurfactant-assisted hydrothermal synthesis of onedimensional $\mathrm{ZnO}$ nanorods for high-performance ethanol gas sensor. Sensor Actuat B-Chem. 2019;286:501-11.

[37] Galstyan V, Poli N, Comini E. Highly Sensitive and Selective $\mathrm{H}_{2} \mathrm{~S}$ Chemical Sensor Based on ZnO Nanomaterial. Appl Sci. 2019;9(6):1167.

[38] Galstyan V, Comini E, Faglia G, Sberveglieri G. $\mathrm{TiO}_{2}$ Nanotubes: Recent Advances in Synthesis and Gas Sensing Properties. Sensors. 2013;13(11):14813-38.

[39] Liu X, Pan K, Wang L, Dong C, Xiao X, Wang Y. Butane detection: W-doped $\mathrm{TiO}_{2}$ nanoparticles for a butane gas sensor with high sensitivity and fast response/recovery. RSC Adv. 2015;5(117):96539-46.

[40] Phanichphant S, Liewhiran C, Wetchakun K, Wisitsoraat A, Tuantranont A. Flame-Made Nb-Doped $\mathrm{TiO}_{2}$ Ethanol and Acetone Sensors. Sensors. 2011;11(1):472-84.

[41] Li G, Cheng Z, Xiang Q, Yan L, Wang X, Xu J. Bimetal $\mathrm{PdAu}$ decorated $\mathrm{SnO}_{2}$ nanosheets based gas sensor with temperature-dependent dual selectivity for detecting formaldehyde and acetone. Sensor Actuat B-Chem. 2019;283:590-601. 
[42] Zhu K, Ma S, Tie Y, Zhang Q, Wang W, Pei S, et al. Highly sensitive formaldehyde gas sensors based on Y-doped $\mathrm{SnO}_{2}$ hierarchical flower-shaped nanostructures. J Alloys Compd. 2019;792:938-44.

[43] Mahajan S, Jagtap S. Metal-oxide semiconductors for carbon monoxide (CO) gas sensing: A review. Appl Mater Today. 2020;18:100483.

[44] Mtz-Enriquez Al, Padmasree KP, Oliva Al, Gomez-Solis C, Coutino-Gonzalez E, Garcia CR, et al. Tailoring the detection sensitivity of graphene based flexible smoke sensors by decorating with ceramic microparticles. Sensor Actuat B-Chem. 2020;305:127466.

[45] Nunes D, Pimentel A, Gonçalves A, Pereira S, Branquinho $\mathrm{R}$, Barquinha $\mathrm{P}$, et al. Metal oxide nanostructures for sensor applications. Semicond Sci Technol. 2019;34(4):043001.

[46] Palzer S. Photoacoustic-Based Gas sensing: A Review. Sensors. 2020;20(9):2745.

[47] Radica F, Mura S, Carboni D, Malfatti L, Garrini S, Enzo S, Della Ventura G, Tranfo G, Marcelli A, Innocenzi P. Phenylmodified hybrid organic-inorganic microporous films as high efficient platforms for styrene sensing. Micropor Mesopor Mat. 2020;294:109877.

[48] De Fonseca B, Rossignol J, Bezverkhyy I, Bellat JP, Stuerga $D$, Pribetich P. Detection of VOCs by microwave transduction using dealuminated faujasite DAY zeolites as gas sensitive materials. Sensor Actuat B-Chem. 2015;213:558-565.

[49] Neil J, Harris BJ, Pulliam RL, Muckle MT, Reynolds R, McDaniel D, Pate BH. Pure rotational spectrometers for trace-level VOC detection and chemical sensing. SPIE Sensing Technology + Applications, 2014, Baltimore, Maryland, United States: 91010B.

[50] Apolonski A, Roy S, Lampe R, Maiti KS. Application of Vibrational spectroscopy in Biology and Medicine. Breath Analysis. Proceedings. 2019;27:26.

[51] Visser T. Infrared Spectroscopy in Environmental Analysis. In Encyclopedia of Analitical Chemistry. John Wiley \& Sons; 2006;1-21.

[52] Ju W, Lu C, Liu C, Jiang W, Zhang Y, Hong F. Rapid Identification of Atmospheric Gaseous Pollutants Using Fourier-Transform Infrared Spectroscopy Combined with Independent Component Analysis. J Spectrosc. 2020;2020:1-14.

[53] Xue D, Wang Y, Zhang Z, Cao J. Porous $\operatorname{In}_{2} \mathrm{O}_{3}$ nanospheres with high methane sensitivity: A combined experimental and first-principle study. Sensor Actuat A-Phys. 2020;305:111944.

[54] Mounasamy V, Mani GK, Ponnusamy D, Tsuchiya K, Reshma $\mathrm{PR}$, Prasad AK, et al. Investigation on $\mathrm{CH}_{4}$ sensing characteristics of hierarchical $\mathrm{V}_{2} \mathrm{O}_{5}$ nanoflowers operated at relatively low temperature using chemiresistive approach. Anal Chim Acta. 2020;1106:148-60.

[55] Kundu S, Kumar A, Sen S, Nilabh A. Bio-synthesis of $\mathrm{SnO}_{2}$ and comparison its $\mathrm{CO}$ sensing performance with conventional processes. J Alloy Compbd. 2020;818:152841.

[56] Sholehah A, Faroz DF, Huda N, Utari L, Septiani NL, Yuliarto B. Synthesis of ZnO Flakes on Flexible Substrate and Its Application on Ethylene Sensing at Room Temperature. Chemosensors. 2020;8(1):2.

[57] Varudkar HA, Umadevi G, Nagaraju P, Dargad JS, Mote VD. Fabrication of Al-doped $\mathrm{ZnO}$ nanoparticles and their application as a semiconductor-based gas sensor for the detection of ammonia. J Mater Sci Mater Electron. 2020;31(15):12579-85.

[58] Dilova T, Atanasova G, Og. Dikovska A, Avdeev G, Machida $M$, Terakawa M, et al. Effect of Pd-decoration on the sensing properties of $\mathrm{ZnO}$ nanostructures. Thin Solid Films. 2020;693:137693.

[59] Liu Y, Wang W, Xu X, Marcel Veder J-P, Shao Z. Recent advances in anion-doped metal oxides for catalytic applications. J Mater Chem A. 2019;7(13):7280-300.

[60] Schneid AC, Quevedo AB, Pereira MB, Araújo PF, Franco N, Machado G, et al. New strategy to obtain high surface area anatase nanotube/AuNP photocatalyst. Nanotechnology. 2018;30(6):065604.

[61] Sugiawati VA, Vacandio F, Galeyeva A, Kurbatov AP, Djenizian T. Enhanced Electrochemical Performance of Electropolymerized Self-Organized $\mathrm{TiO}_{2}$ Nanotubes Fabricated by Anodization of Ti Grid. Front Phys. 2019;7:179.

[62] Galstyan V, Vomiero A, Concina I, Braga A, Brisotto M, Bontempi E, et al. Vertically Aligned $\mathrm{TiO}_{2}$ Nanotubes on Plastic Substrates for Flexible Solar Cells. Small. 2011;7(17):2437-42.

[63] Castro AGB, Bastos AC, Galstyan V, Faglia G, Sberveglieri G, Salvado IMM. Synthesis and electrochemical study of a hybrid structure based on PDMS-TEOS and titania nanotubes for biomedical applications. Nanotechnology. 2014;25(36):365701.

[64] Galstyan V, Comini E, Faglia G, Sberveglieri G. Synthesis of self-ordered and well-aligned $\mathrm{Nb}_{2} \mathrm{O}_{5}$ nanotubes. CrystEngComm. 2014;16(44):10273-9.

[65] Islam S. Fast responsive anatase nanoparticles coated fiber optic pH sensor. J Alloys Compd. 2021;850:156246.

[66] Galstyan V. Porous $\mathrm{TiO}_{2}$-Based Gas Sensors for Cyber Chemical Systems to Provide Security and Medical Diagnosis. Sensors. 2017;17(12):2947.

[67] Galstyan V, Bhandari M, Sberveglieri V, Sberveglieri G, Comini E. Metal Oxide Nanostructures in Food Applications: Quality Control and Packaging. Chemosensors. 2018;6(2):16.

[68] Sahay PP. Zinc oxide thin film gas sensor for detection of acetone. J Mater Sci. 2005; 40(16):4383-5.

[69] Gurlo A. Insights into the Mechanism of Gas Sensor Operation. In Metal Oxide Nanomaterials for Chemical Sensors; Carpenter, M.A., Mathur, S., Kolmakov, A., Editors. New York: Springer; 2013;1,13-34.

[70] Ramanavicius S, Tereshchenko A, Karpicz R, Ratautaite V, Bubniene U, Maneikis A, et al. $\mathrm{TiO}_{2-x} / \mathrm{TiO}_{2}$-Structure Based 'Self-Heated' Sensor for the Determination of Some Reducing Gases. Sensors. 2020;20(1):74.

[71] Elger AK, Hess C. Application of Raman Spectroscopy to Working Gas Sensors: From in situ to operando Studies. Sensors. 2019;19(23):5075.

[72] Gayraud N, Kornaszewski tW, Stone JM, Knight JC, Reid DT, Hand DP, et al. Mid-infrared gas sensing using a photonic bandgap fiber. Appl Opt. 2008;47(9):1269-77.

[73] Plunkett S, Parrish ME, Shafer KH, Nelson D, Shorter J, Zahniser M. Time-resolved analysis of cigarette combustion gases using a dual infrared tunable diode laser system. Vib Spectrosc. 2001;27(1):53-63.

[74] Arunajatesan V, Subramaniam B, Hutchenson KW, Herkes FE. In situ FTIR investigations of reverse water gas shift 
reaction activity at supercritical conditions. Chem Eng Sci. 2007;62(18):5062-9.

[75] Neese CF, Medvedev IR, Plummer GM, Frank AJ, Ball CD, Lucia FCD. Compact Submillimeter/Terahertz Gas Sensor with Efficient Gas Collection, Preconcentration, and ppt Sensitivity. IEEE Sens J. 2012;12(8):2565-74.

[76] Bigourd D, Cuisset A, Hindle F, Matton S, Fertein E, Bocquet $R$, et al. Detection and quantification of multiple molecular species in mainstream cigarette smoke by continuous-wave terahertz spectroscopy. Opt Lett. 2006;31(15):2356-8.

[77] Kortenbruck K, Pohrer B, Schluecker E, Friedel F, IvanovicBurmazovic I. Determination of the diffusion coefficient of $\mathrm{CO}_{2}$ in the ionic liquid EMIM NTf, using online FTIR measurements. J Chem Thermodyn. 2012;47:76-80.

[78] Sánchez A, Eddings E, Mondragón F. Fourier Transform Infrared (FTIR) Online Monitoring of $\mathrm{NO}, \mathrm{N}_{2} \mathrm{O}$, and $\mathrm{CO}_{2}$ during Oxygen-Enriched Combustion of Carbonaceous Materials. Energ Fuels. 2010;24(9):4849-53.

[79] Fosnight AM, Moran BL, Medvedev IR. Chemical analysis of exhaled human breath using a terahertz spectroscopic approach. Appl Phys Lett. 2013;103(13):133703.

[80] Banwell CN, McCash EM. Fundamentals of molecular spectroscopy. McGraw-Hill Education: London; 1994.

[81] Hodgkinson J, Tatam RP. Optical gas sensing: a review. Meas Sci Technol. 2012;24(1):012004.

[82] Seo M, Park H.-R. Terahertz Biochemical Molecules-specific sensors. Adv Opt Mater. 2019; 8(3).

[83] Tonouchi M. Cutting-edge terahertz technology. Nat Photonics. 2007;1(2):97-105.

[84] Lee YS. Principles of Terahertz Science and Technology. Springer; 2008.

[85] Zhang XC, Xu J. Introduction to THz wave photonics. Springer; 2010.

[86] Ikeda T, Matsushita A, Tatsuno M, Minami Y, Yamaguchi M, Yamamoto K, et al. Investigation of inflammable liquids by terahertz spectroscopy. Appl Phys Lett. 2005;87(3):034105.

[87] Mittleman DM, Jacobsen RH, Neelamani R, Baraniuk RG, Nuss MC. Gas sensing using terahertz time-domain spectroscopy. Appl Phys B. 1998;67(3):379-90.

[88] Gerecht E, Douglass KO, Plusquellic DF. Chirped-pulse terahertz spectroscopy for broadband trace gas sensing. Opt Express. 2011;19(9):8973-84.

[89] Lin H, Withayachumnankul W, Fischer B, Mickan S, Abbott D. Gas recognition with terahertz time-domain spectroscopy and spectral catalog: a preliminary study. Terahertz Photonics; 2008;6840, DOI: 10.1117/12.760558.

[90] Kindt JT, Schmuttenmaer CA. Far-Infrared Dielectric Properties of Polar Liquids Probed by Femtosecond Terahertz Pulse Spectroscopy. J Phys Chem. 1996;100(24):10373-9.

[91] Fedulova E, Nazarov M, Angeluts A, Kitai M, Sokolov V, Shkurinov A. Studying of dielectric properties of polymers in the terahertz frequency range. Saratov Fall Meeting 2011: Optical technologies in biophysics and medicine XIII; 2011.

[92] De Lucia FC. Spectroscopy in the Terahertz Spectral Region. In Sensing with Terahertz Radiation; Mittleman, D., Editors. Berlin Heidelberg: Springer; 2003;85,39-115.

[93] D’Arco A, Di Fabrizio M, Dolci V, Marcelli A, Petrarca M, Della Ventura G, et al. Characterization of volatile organic compounds (VOCs) in their liquid-phase by terahertz timedomain spectroscopy. Biomed Opt Express. 2020;11(1):1-7.

[94] Naftaly M, Vieweg N, Deninger A. Industrial Applications of Terahertz Sensing: State of Play. Sensors. 2019;19(19):4203.

[95] Jie C, Kazuki N, Xin Z, Takahiko M, Takeo M, Francis H, et al. Adaptive-sampling near-Doppler-limited terahertz dual-comb spectroscopy with a free-running single-cavity fiber laser. Adv Photonics 2020;2(3):1-11.

[96] Trofimov VA, Varentsova SA. A Possible Way for the Detection and Identification of Dangerous Substances in Ternary Mixtures Using THz Pulsed Spectroscopy. Sensors. 2019;19(10):2365.

[97] Medvedev IR, Neese CF, Plummer GM, De Lucia FC. Submillimeter spectroscopy for chemical analysis with absolute specificity. Opt Lett. 2010;35(10):1533-5.

[98] Yang L, Guo T, Zhang X, Cao S, Ding X. Toxic chemical compound detection by terahertz spectroscopy: a review. J Rev Anal Chem. 2018;37(3):20170021.

[99] Ronne C, Jensby K, Loughnane BJ, Fourkas J, Nielsen OF, Keiding SRR. Temperature dependence of the dielectric function of $\mathrm{C}_{6} \mathrm{H}_{6}(\mathrm{l})$ and $\mathrm{C}_{6} \mathrm{H}_{5} \mathrm{CH}_{3}(\mathrm{l})$ measured with $\mathrm{THz}$ spectroscopy. J Chem Phys. 2000;113(9):3749-56.

[100] Bian J, Zhu Y, Jia X, Chen L, Peng Y, Yang Y, et al. Investigation of aqueous acetone solution with $\mathrm{THz}$ pulse spectroscopy. Front Optoelectron. 2011;4(4):444-7.

[101] Barnes RB, Benedict WS, Lewis CM. The Far Infrared Absorption of Benzene. Phys Rev. 1935;47(2):129-30.

[102] Mrozek RCF, Sherman WF, Wilkinson GR. Far infrared spectra of liquid and solid benzene. Microchim Acta. 1988;95(1):349-52.

[103] Mickan S, Abbott D, Munch J, Zhang XC, van Doorn T. Analysis of system trade-offs for terahertz imaging. Microelectr J. 2000;31(7):503-14.

[104] Burford N, El-Shenawee M.O. Review of terahertz photoconductive antenna technology. Opt Eng. 2017;56(1):010901.

[105] Zhang XC, Ma XF, Jin Y, Lu TM, Boden EP, Phelps PD, et al. Terahertz optical rectification from a nonlinear organic crystal. Appl Phys Lett. 1992;61(26):3080-2.

[106] Dexheimer SL. Terahertz Spectroscopy: Principles and Applications. CRC Press; 2017.

[107] Naftaly M, Clarke RG, Humphreys DA, Ridler NM. Metrology State-of-the-Art and Challenges in Broadband PhaseSensitive Terahertz Measurements. Proceedings of the IEEE. 2017;99:1-15.

[108] D’Arco A, Di Fabrizio M, Dolci V, Petrarca M, Lupi S. THz Pulsed Imaging in Biomedical Applications. J Cond Matt Phys. 2020;5(2):25.

[109] Di Fabrizio M, D’Arco A, Mou S, Palumbo L, Petrarca M, Lupi S. Performance Evaluation of a THz pulsed Imaging System: Point Spread Function, Broadband THz Beam Visualization and Image Reconstruction. Appl Sci. 2021;11:562.

[110] Kong DY, Wu XJ, Wang B, Gao Y, Dai J, Wang L, et al. High resolution continuous wave terahertz spectroscopy on solid-state samples with coherent detection. Opt Express. 2018;26:17964-76.

[111] Deninger AJ, Roggenbuck A, Schindler S, Preu S. 2.75 $\mathrm{THz}$ tuning with a triple-DFB laser system at $1550 \mathrm{~nm}$ and InGaAs photomixers. J Infrared Millim Terahertz Waves. 2015;36:269-77. 
[112] Yang C-C, Chen K-Y, Su Y-K. TiO N Nano Flowers Based EGFET Sensor for pH Sensing. Coatings. 2019;9(4):251.

[113] Li Y, Chen N, Deng D, Xing X, Xiao X, Wang Y. Formaldehyde detection: $\mathrm{SnO}_{2}$ microspheres for formaldehyde gas sensor with high sensitivity, fast response/recovery and good selectivity. Sensor Actuat B-Chem. 2017;238:264-73.

[114] Thai NX, Van Duy N, Hung CM, Nguyen H, Tonezzer M, Van Hieu N, et al. Prototype edge-grown nanowire sensor array for the real-time monitoring and classification of multiple gases. Journal of Science: Adv Mater Dev. 2020;5(3):409-16.

[115] Acharyya S, Jana B, Nag S, Saha G, Guha PK. Single resistive sensor for selective detection of multiple VOCs employing $\mathrm{SnO}_{2}$ hollowspheres and machine learning algorithm: A proof of concept. Sensor Actuat B-Chem. 2020;321:128484.

[116] Li SH, Chu Z, Meng FF, Luo T, Hu XY, Huang SZ, et al. Highly sensitive gas sensor based on $\mathrm{SnO}_{2}$ nanorings for detection of isopropanol. J Alloys Compd. 2016;688:712-7.

[117] Lee S-H, Galstyan V, Ponzoni A, Gonzalo-Juan I, Riedel R, Dourges $\mathrm{M}-\mathrm{A}$, et al. Finely Tuned $\mathrm{SnO}_{2}$ Nanoparticles for Efficient Detection of Reducing and Oxidizing Gases: The Influence of Alkali Metal Cation on Gas-Sensing Properties. ACS Appl Mater Interfaces. 2018;10(12):10173-84.

[118] Mao JN, Hong B, Chen HD, Gao MH, Xu JC, Han YB, et al. Highly improved ethanol gas response of $n$-type $\alpha-\mathrm{Fe}_{2} \mathrm{O}_{3}$ bunched nanowires sensor with high-valence donor-doping. J Alloys Compd. 2020;827:154248.

[119] De Pascali C, Signore MA, Taurino A, Francioso L, Macagnano A, Avossa J, et al. Investigation of the Gas-Sensing Performance of Electrospun $\mathrm{TiO}_{2}$ Nanofiber-Based Sensors for Ethanol Sensing. IEEE Sens J. 2018;18(18):7365-74.

[120] Galstyan V, Poli N, D’Arco A, Macis S, Lupi S, Comini E. A novel approach for green synthesis of $\mathrm{WO}_{3}$ nanomaterials and their highly selective chemical sensing properties. J Mater Chem A. 2020;8:20373-85.

[121] Rai P, Yoon J-W, Kwak C-H, Lee J-H. Role of Pd nanoparticles in gas sensing behaviour of $\mathrm{Pd@In} \mathrm{O}_{3}$ yolk-shell nanoreactors. J Mater Chem A. 2016;4(1):264-9.

[122] Tiwary P, Mahapatra R, Chakraborty AK. ZnO nanobristles prepared by one-step thermal decomposition of zinc nitrate as ultra-high response ethanol sensor at room temperature. J Mater Sci Mater Electron. 2019;30(6):5464-9.

[123] Galstyan V, Comini E, Baratto C, Ponzoni A, Ferroni M, Poli N, et al. Large surface area biphase titania for chemical sensing. Sensor Actuat B-Chem. 2015;209:1091-6.

[124] Schwoebel H, Schubert R, Sklorz M, Kischkel S, Zimmermann $\mathrm{R}$, Schubert JK, et al. Phase-resolved real-time breath analysis during exercise by means of smart processing of PTR-MS data. Anal Bioanal Chem. 2011;401(7):2079.

[125] Deng C, Zhang J, Yu X, Zhang W, Zhang X. Determination of acetone in human breath by gas chromatography-mass spectrometry and solid-phase microextraction with on-fiber derivatization. J Chromatogr B. 2004;810(2):269-75.

[126] Liu W, Xie Y, Chen T, Lu Q, Ur Rehman S, Zhu L. Rationally designed mesoporous $\ln _{2} \mathrm{O}_{3}$ nanofibers functionalized Pt catalysts for high-performance acetone gas sensors. Sensor Actuat B-Chem. 2019;298:126871.
[127] Xu X, Chen Y, Zhang G, Ma S, Lu Y, Bian H, et al. Highly sensitive VOCs-acetone sensor based on Ag-decorated $\mathrm{SnO}_{2}$ hollow nanofibers. J Alloys Compd. 2017;703:572-9.

[128] Inderan V, Arafat MM, Kumar S, Haseeb ASMA, Jiang Z-T, Altarawneh M, et al. Study of structural properties and defects of $\mathrm{Ni}$-doped $\mathrm{SnO}_{2}$ nanorods as ethanol gas sensors. Nanotechnology. 2017;28(26):265702.

[129] Galstyan V, Comini E, Faglia G, Vomiero A, Borgese L, Bontempi $E$, et al. Fabrication and investigation of gas sensing properties of $\mathrm{Nb}$-doped $\mathrm{TiO}_{2}$ nanotubular arrays. Nanotechnology. 2012;23(23):235706.

[130] Arbiol J, Cerda J, Dezanneau G, Cirera A, Peiro F, Cornet A, et al. Effects of $\mathrm{Nb}$ doping on the $\mathrm{TiO}_{2}$ anatase-to-rutile phase transition. J Appl Phys. 2002;92(2):853-61.

[131] Zhao T, Qiu P, Fan Y, Yang J, Jiang W, Wang L, et al. Hierarchical Branched Mesoporous $\mathrm{TiO}_{2}-\mathrm{SnO}_{2}$ Nanocomposites with Well-Defined $n-n$ Heterojunctions for Highly Efficient Ethanol Sensing. Adv Sci. 2019;6(24):1902008.

[132] Galstyan V, Ponzoni A, Kholmanov I, Natile MM, Comini E, Nematov S, et al. Investigation of Reduced Graphene Oxide and a $\mathrm{Nb}$-Doped $\mathrm{TiO}_{2}$ Nanotube Hybrid Structure to Improve the Gas-Sensing Response and Selectivity. ACS Sens. 2019;4(8):2094-100.

[133] Motsoeneng RG, Kortidis I, Rikhotso R, Swart H, Ray SS, Motaung DEJS, et al. Temperature-dependent response to $\mathrm{C}_{3} \mathrm{H}_{7} \mathrm{OH}$ and $\mathrm{C}_{2} \mathrm{H}_{5} \mathrm{OH}$ vapors induced by deposition of $\mathrm{Au}$ nanoparticles on $\mathrm{SnO}_{2} / \mathrm{NiO}$ hollow sphere-based conductometric sensors. Sensor Actuat B-Chem. 2020;316:128041.

[134] Tomer VK, Duhan S. Ordered mesoporous Ag-doped $\mathrm{TiO}_{2} /$ $\mathrm{SnO}_{2}$ nanocomposite based highly sensitive and selective VOC sensors. J Mater Chem A. 2016;4(3):1033-43.

[135] Shruthi J, Jayababu N, Reddy MVR. Synthesis of $\mathrm{Y}_{2} \mathrm{O}_{3}-\mathrm{ZnO}$ nanocomposites for the enhancement of room temperature 2-methoxyethanol gas sensing performance. J Alloys Compd. 2019;798:438-45.

[136] Jayababu N, Poloju M, Shruthi J, Reddy MVR. Semi shield driven $\mathrm{p}-\mathrm{n}$ heterostructures and their role in enhancing the room temperature ethanol gas sensing performance of $\mathrm{NiO} / \mathrm{SnO}_{2}$ nanocomposites. Ceram Int. 2019;45(12):15134-42.

[137] Xing XX, Chen N, Yang Y, Zhao RJ, Wang ZZ, Wang ZD, et al. Pt-Functionalized Nanoporous $\mathrm{TiO}_{2}$ Nanoparticles with Enhanced Gas Sensing Performances Toward Acetone. IPSS a-Applications and Materials Science. 2018;215(14):1800100.

[138] Guo WW. Design of Gas Sensor Based on Fe-Doped ZnO Nanosheet-Spheres for Low Concentration of Formaldehyde Detection. J Electrochem Soc. 2016;163(9):B517-B25.

[139] Feng C, Jiang Z, Chen B, Cheng P, Wang Y, Huang C. Aluminum-doped $\mathrm{NiO}$ nanofibers as chemical sensors for selective and sensitive methanol detection. Anal Methods. 2019;11(5):575-81.

[140] Lin CH, Grant RH, Heber AJ, Johnston CT. Application of open-path Fourier transform infrared spectroscopy (OP-FTIR) to measure greenhouse gas concentrations from agricultural fields. Atmos Meas Tech. 2019;12(6):3403-15.

[141] Ycas G, Giorgetta FR, Cossel KC, Waxman EM, Baumann E, Newbury NR, et al. Mid-infrared dual-comb spectroscopy 
of volatile organic compounds across long open-air paths. Optica. 2019;6(2):165-8.

[142] Yu M, Okawachi Y, Griffith AG, Picqué N, Lipson M, Gaeta AL. Silicon-chip-based mid-infrared dual-comb spectroscopy. Nat Commun. 2018;9(1):1869.

[143] Chen Z, Yan M, Hänsch TW, Picqué N. A phase-stable dualcomb interferometer. Nat Commun. 2018;9(1):3035.

[144] Griffiths PR. Fourier transform infrared spectrometry. Science. 1983;222(4621):297-302.

[145] Xiaoxing Z, Yin Z, Ju T, Zhaolun C, Yanglong L, Hong Z, et al. Optical technology for detecting the decomposition products of $\mathrm{SF}_{6}$ : a review. Opt Eng. 2018;57(11):1-12.

[146] Zhou H-Y, Ma G-M, Wang Y, Qin W-Q, Jiang J, Yan C, et al. Optical sensing in condition monitoring of gas insulated apparatus: a review. High Voltage. 2019;4(4):259-70.

[147] Zhang X, Liu H, Ren J, Li J, Li X. Fourier transform infrared spectroscopy quantitative analysis of $\mathrm{SF}_{6}$ partial discharge decomposition components. Spectrochim Acta A. 2015;136:884-9.

[148] Ouyang T, Wang C, Yu Z, Stach R, Mizaikoff B, Liedberg B, et al. Quantitative Analysis of Gas Phase IR Spectra Based on Extreme Learning Machine Regression Model. Sensors. 2019;19(24):5535

[149] Delaney MF, Warren FV, Hallowell JR. Quantitative evaluation of library searching performance. Anal Chem. 1983;55(12):1925-9.

[150] Lavine BK, Nuguru K, Mirjankar N, Workman J. Pattern Recognition Assisted Infrared Library Searching. Appl Spectrosc. 2012;66(8):917-25.

[151] Yang H, Griffiths PR. Encoding FT-IR Spectra in a Hopfield Network and Its Application to Compound Identification in Open-Path FT-IR Measurements. Anal Chem. 1999;71(16):3356-64.

[152] Li Y, Wang J-D, Huang Z-H, Xu H-Q, Zhou X-T. Monitoring leaking gases by OP-FTIR remote sensing. J Environ Sci Health-A. 2002;37(8):1453-62.

[153] Li Y, Yang S, Wang J, Gu B, Liu F. Simultaneous Determination of Multicomponents in Air Toxic Organic Compounds Using Artificial Neural Networks in Ftir Spectroscopy. Spectrosc Lett. 1999;32(3):421-9

[154] Tofani S, Fuscaldo W. Fabry-Perot Cavity Leaky Wave Antennas with Tunable Features for Terahertz Applications. Condens Matter 2020;5(1):11.

[155] D’Arco A, Tomarchio L, Dolci V, Di Pietro P, Perucchi A, Mou $S$, et al. Broadband Anisotropic Optical Properties of the Terahertz Generator HMQ-TMS Organic Crystal. Condens Matter. 2020;5(3):47.

[156] Jazbinsek M, Puc U, Abina A, Zidansek A. Organic Crystals for THz Photonics. Appl Sci. 2019;9(5):882.

[157] Perucchi A, Di Mitri S, Penco G, Allaria E, Lupi S. The TeraFERMI terahertz source at the seeded FERMI freeelectron-laser facility. Rev Sci Instrum. 2013;84(2):022702.

[158] Chiadroni E, Bacci A, Bellaveglia M, Boscolo M, Castellano $M$, Cultrera $L$, et al. The SPACRC linear accelerator based terahertz source. Appl Phys Lett. 2013;102:094101.

[159] Dai J, Liu J, Zhang X. Terahertz Wave Air Photonics: Terahertz Wave Generation and Detection with Laser-Induced Gas Plasma. IEEE J of Selected Topics in Quantum Electronics. 2011;17(1):183-90.
[160] Winnewisser C, Jepsen PU, Schall M, Schyja V, Helm H Electro-optic detection of $\mathrm{THz}$ radiation in $\mathrm{LiTaO}_{3}, \mathrm{LiNbO}_{3}$ and ZnTe. Appl Phys Lett. 1997;70(23):3069-71.

[161] Hesler J, Prasankumar R, Tignon J. Advances in terahertz solid-state physics and devices. J Appl Phys. 2019;126:110401.

[162] Saffian R, Ghazi G, Mohammadian N. Review of photomixing continuous-wave terahertz systems and current application trends in terahertz domain. Opt Eng. 2019;58(11):110901.

[163] Liao GQ, Li YT. Review of Intense Terahertz Radiation from Relativistic Laser-Produced Plasmas. IEEE T Plasma Sci. 2019;47(6):3002-08.

[164] Rezvani J, Di Gioacchino D, Gatti C, Poccia N, Ligi C, Tocci S, et al. Tunable Vortex Dynamics in Proximity Junction Arrays: A Possible Accurate and Sensitive 2D THz Detector. Acta Phys Pol A. 2020.137(1):17-20.

[165] Zhang Y, Hosono S, Nagai N, Song SH, Hirakawa K. Fast and sensitive bolometric terahertz detection at room temperature through thermomechanical transduction. J Appl Phys. 2019;125(15):151602.

[166] Hochrein T. Markets, Availability, Notice, and Technical Performance of Terahertz Systems: Historic Development, Present, and Trends. J Infrared Millim Terahertz Waves. 2015;36(3):235-54.

[167] Macis S, Tomarchio L, Tofani S, Rezvani SJ, Faillace L, Lupi $S$, et al. Angular Dependence of Copper Surface Damage Induced by an Intense Coherent THz Radiation Beam. J Cond Mat Phys. 2020;5(1):16

[168] Irizawa A, Fujimoto M, Kawase K, Kato R, Fujiwara H, Higashiya A, et al. Spatially Resolved Spectral Imaging by A THz-FEL. J Cond Matt Phys. 2020;5(2):38.

[169] Stoik CD, Bohn MJ, Blackshire JL. Nondestructive evaluation of aircraft composites using transmissive terahertz time domain spectroscopy. Opt Express. 2008;16(21):17039-51

[170] Giuliano BM, Gavdush AA, Müller B, Zaytsev KI, Grassi T, Ivlev AV, et al. Broadband spectroscopy of astrophysical ice analogues-I. Direct measurement of the complex refractive index of CO ice using terahertz time-domain spectroscopy. Astron Astrophys. 2019;629:A112.

[171] Cosentino A. Terahertz and Cultural Heritage Science: Examination of Art and Archaeology. Technologies. 2016;4(1):6.

[172] Guerboukha H, Nallappan K, Skorobogatiy M. Toward realtime terahertz imaging. Adv Opt Photon. 2018;10(4):843-938.

[173] Yang X, Zhao X, Yang K, Liu Y, Liu Y, Fu W, et al. Biomedical Applications of Terahertz Spectroscopy and Imaging. Trends Biotechnol. 2016;34(10):810-24

[174] Son JH, Oh SJ, Cheon H. Potential clinical applications of terahertz radiation. J Appl Phys. 2019;125(19):190901.

[175] D’Arco A, Mussi V, Petrov S, Tofani S, Petrarca M, Beccherelli $\mathrm{R}$, et al. Fabrication and spectroscopic characterization of graphene transparent electrodes on flexible cyclo-olefin substrates for terahertz electro-optic applications. Nanotech. 2020;31(36):364006.

[176] Giorgianni F, Sakai J, Lupi S. Overcoming the thermal regime for the electric-field driven Mott transition in vanadium sesquioxide. Nat Comm. 2019;10(1):1159. 
[177] Giorgianni F, Chiadroni E, Rovere A, Cestelli-Guidi M, Perucchi $A$, Bellaveglia $M$, et al. Strong nonlinear terahertz response induced by Dirac surface states in $\mathrm{Bi}_{2} \mathrm{Se}_{3}$ topological insulator. Nat Comm. 2016;7(1):11421.

[178] Curcio A, Marocchino A, Dolci V, Lupi S, Petrarca M. Resonant plasma excitation by single-cycle THz pulses. Sci Rep. 2018;8(1):1052.

[179] Balerna A, Bartocci S, Batignani G, Cianchi A, Chiadroni E, Coreno M, et al. The Potential of EuPRAXIA@SPARC_LAB for Radiation Based Techniques. J Cond Matt Phys. 2019;4(1):30.

[180] Federici JF, Schulkin B, Huang F, Gary D, Barat R, Oliveira F, et al. THz imaging and sensing for security applicationsexplosives, weapons and drugs. Semicond Sci Tech. 2005;20(7):S266-S80

[181] De Lucia FC. The submillimeter: A spectroscopist's view. J Mol Spectrosc. 2010;261(1):1-17

[182] Pickett HM, Poynter RL, Cohen EA, Delitsky ML, Pearson JC, Muller HSP. Submillimeter, Millimeter, and Microwave Spectral Line Catalog. J Quant Spectrosc Radiat Transf. 1998;60(5):883-90.

[183] Medvedev IR, Behnke M, De Lucia FC. Fast analysis of gases in the submillimeter/terahertz with "absolute" specificity. Appl Phys Lett. 2005;86(15):154105.

[184] Smith RM, Arnold MA. Selectivity of Terahertz Gas-Phase Spectroscopy. Anal Chem. 2015;87(21):10679-83.

[185] Graber B, Kim C, Wu DH. High SNR single measurements of trace gas phase spectra at $\mathrm{THz}$ frequencies. Appl Phys Lett. 2017;111(22):221107.

[186] Hsieh YD, Nakamura S, Abdelsalam DG, Minamikawa T, Mizutani Y, Yamamoto H, et al. Dynamic terahertz spectroscopy of gas molecules mixed with unwanted aerosol under atmospheric pressure using fiber-based asynchronousoptical-sampling terahertz time-domain spectroscopy. Sci Rep. 2016;6(1):1-10.

[187] Kilcullen P, Hartley ID, Jensen ET, Reid M. Terahertz Time Domain Gas-phase Spectroscopy of Carbon Monoxide. J Infrared Millim Terahertz Waves. 2015;36(4):380-9.

[188] Hsieh YD, Kimura H, Hayashi K, Minamikawa T, Mizutani $\mathrm{Y}$, Yamamoto H, et al. Terahertz Frequency-Domain Spectroscopy of Low-Pressure Acetonitrile Gas by a Photomixing Terahertz Synthesizer Referenced to Dual Optical Frequency Combs. J Infrared Millim Terahertz Waves. 2016;37(9):903-15.

[189] Chen L, Oishi S. Terahertz Time-Domain Spectroscopy of Organic Gases. Review Laser Eng. 2006;34(3):251-4.

[190] Shimizu N, Ikari T, Kikuchi K, Matsuyama K, Wakatsuki A, Kohjiro S, et al. Remote gas sensing in full-scale fire with sub-terahertz waves. IEEE MTT-S International Microwave Symposium; 2011:1-4, DOI: 10.1109/ MWSYM.2011.5972655.

[191] Choi J, Ryu SY, Kwon WS, Kim KS, Kim S. Compound Explosives Detection and Component Analysis via Terahertz Time-Domain Spectroscopy. Korean J Opt Photon. 2013;17(5):454-60

[192] Agranat MB, Il'ina IV, Sitnikov DS. Application of terahertz spectroscopy for remote express analysis of gases. High Temp High Pressures. 2017;55(6):922-34.
[193] Liu H, Zhong H, Karpowicz N, Chen Y, Zhang X. Terahertz Spectroscopy and Imaging for Defense and Security Applications. Proceedings of the IEEE. 2007;95(8):1514-27.

[194] Yang YH, Shutler A, Grischkowsky D. Measurement of the transmission of the atmosphere from 0.2 to $2 \mathrm{THz}$. Opt Express. 2011;19(9):8830-8.

[195] Sitnikov DS, Romashevskiy SA, Pronkin AA, Ilina IV. Openpath gas detection using terahertz time-domain spectroscopy. J Phys Conf Ser. 2019;1147(1):012061

[196] Demers JR, Garet F, Coutaz JL. A UAV-mounted THz spectrometer for real-time gas analysis. SPIE 10531, Terahertz, RF, Millimiter and Submillimiter-Wave Technology and applications XI, 105310K; 2018, DOI: 10.1117/12.2292783.

[197] Zhang H, Zhang Z, Zhao X,Zhang X, Zhang T, Cao C, Yu Y. Qualitative and quantitative analysis of atmospheric methanol using a continuous-wave terahertz spectrometer. Chinese Opt. Lett. 2018;16(10):103001.

[198] Hepp C, Lüttjohann S, Roggenbuck A, Deninger A, Nellen S, Göbel T, et al. A cw-terahertz gas analysis system with ppm detection limits. 41st International Conference on Infrared, Millimeter, and Terahertz waves (IRMMW-THz); 2016, DOI: 10.1109/IRMMW-THz.2016.7758344.

[199] Schmalz K, Rothbart N, Neumaier PF, Borngräber J, Hübers H, Kissinger D. Gas Spectroscopy System for Breath Analysis at mm-wave/THz Using SiGe BiCMOS Circuits. IEEE Trans Microw Theory Tech. 2017;65(5):1807-18.

[200] Medvedev IR, Schueler R, Thomas J, Kenneth 0, $\mathrm{Nam} \mathrm{H}$, Sharma N, et al. Analysis of exhaled human breath via terahertz molecular spectroscopy. 41st International Conference on Infrared, Millimeter, and Terahertz waves (IRMMW-THz); 2016, DOI: 10.1109/ IRMMW-THz.2016.7758450.

[201] Rothbart N, Holz O, Koczulla R, Schmalz K, Hübers HW. Analysis of Human Breath by Millimeter-Wave/Terahertz Spectroscopy. Sensors. 2019;19(12):2719.

[202] Shi X, Zhao Z, Han Z. Highly sensitive and selective gas sensing using the defect mode of a compact terahertz photonic crystal cavity. Sensor Actuat B-Chem. 2018;274:188-93.

[203] Hameed MFO, Esmail MSM, Obayya SS. Terahertz photonic crystal fiber polarization rotator. J Opt Soc Am B. 2020;37(10):2865-72.

[204] Chen T, Han Z, Liu J, Hong Z. Terahertz gas sensing based on a simple one-dimensional photonic crystal cavity with high-quality factors. Appl Opt. 2014;53(16):3454-8.

[205] Benz A, Deutsch C, Brandstetter M, Andrews AM, Klang P, Detz $\mathrm{H}$, et al. Terahertz active photonic crystals for condensed gas sensing. Sensors. 2011;11(12): 6003-14.

[206] Limaj O, Ortolani M, Giliberti V, Di Gaspare A, Mattioli F, Lupi S. Field distribution and quality factor of surface plasmon resonances of metal meshes for mid-infrared sensing. Plasmonics. 2013;8(2):851-8.

[207] Hassani A, Skorobogatiy M. Surface plasmon resonance-like integrated sensor at terahertz frequencies for gaseous analytes. Opt Express. 2008;16(25):20206-14.

[208] You B, Lu JY, Yu CP, Liu TA, Peng JL. Terahertz refractive index sensors using dielectric pipe waveguides. Opt Express. 2012;20(6):5858-66. 
[209] Mishra GP, Kumar D, Chaudhary VS, Sharma S. Terahertz refractive index sensor with high sensitivity based on two-core photonic crystal fiber. Microw Opt Technol Lett. 2020;1-8.

[210] Mendis R, Astely V, Liu J, Mittleman DM. Terahertz microfluidic sensor based on a parallel-plate waveguide resonant cavity. Appl Phys Lett. 2009;95(17):171113.

[211] Vogt DW, Jones AH, Leonhardt R. Terahertz Gas-Phase Spectroscopy Using a Sub-Wavelength Thick Ultrahigh-Q Microresonator. Sensors. 2020;20(10):3005.

[212] Kim HJ, Kim YY, Lee KW. Sensing characteristics of the organic vapors according to the reflectance spectrum in the porous silicon multilayer structure. Sensor Actuat A-Phys. 2011;165: 276-79.

[213] Kelly TL, Garcia Sega A, Sailor MJ. Identification and quantification of organic vapors by time-resolved diffusion in stacked mesoporous photonic crystals. Nano Lett. 2011;11(8):3169-73.

[214] Yebo NA, Lommens P, Hens Z, Baets R. An integrated optic ethanol vapor sensor based on a siliconon-insulator microring resonator coated with a porous $\mathrm{ZnO}$ film. Opt. Express. 2010;18(11):11859-66.

[215] Chen HW, Wu RJ, Chan KH, Sun YL, Su PG. The application of $\mathrm{CNT} /$ Nafion composite material humidity sensing measurement. Sensor Actuat B-Chem. 2005;104:80-4.
[216] Xu P, Yu H, Li X. Functionalized mesoporous silica for microgravimetric sensing of trace chemical vapors. Anal Chem. 2011;83(9):3448-54.

[217] Borwen Y, Ho CH, Zheng W], and Lu JY. Terahertz volatile gas sensing by using polymer microporous membranes. Opt Express. 2015;23(3):2048-57.

[218] Harmon SA, Cheville RA. Part-per-million gas detection from long-baseline THz spectroscopy. Appl Phys Lett. 2004, $85: 2128$.

[219] Neumaier PFX, Schmalz K, Borngraber J, Wylde R, Hubers HW. Terahertz gas-phase spectroscopy: chemometrics for security and medical applications. Analyst. 2015;140:213-22.

[220] Mihrin D, Jakobsen PW, Voute A, Manceron L, Wugt Larsen R. High-resolution synchrotron terahertz investigation of the large-amplitude hydrogen bond librational band of $(\mathrm{HCN})_{2}$. Phys Chem Chem Phys. 2018;20:8241-6.

[221] Tanno T, Watanabe Y, Umeno K, Matsuoka A, Matsumura H, Odaka M, Ogawa N. In Situ Observation of Gas Adsorption onto ZIF-8 Using Terahertz Waves. J Phys Chem C. 2017;121(33):17921-4.

[222] Hindle F, Cuisset A, Bocquet R, Mouret G. Continuous-wave terahertz by photomixing: applications to gas phase pollutant detection and quantification. Comptes Rendus Physique. 2008;9(2):262-75. 